\title{
1 GENETIC ARCHITECTURE OF DIVERGENCE: THE SELFING SYNDROME IN
}

2 IPOMOEA LACUNOSA

3 J. L. Rifkin, G. Cao, and M. D. Rausher

4

\section{ABSTRACT}

- Premise of the study Highly selfing plant species frequently display a distinctive suite of traits termed the "selfing syndrome." This study tests the hypothesis that these traits are grouped into correlated evolutionary modules and determines the degree of independence between such modules.

- Methods We evaluated phenotypic correlations and QTL overlaps in F2 offspring of a cross between the morning glories Ipomoea lacunosa and I. cordatotriloba and investigated how traits clustered into modules at both the phenotypic and genetic level. We then compared our findings to other QTL studies of the selfing syndrome.

- Key results In the I. lacunosa selfing syndrome, traits group into modules that display correlated evolution within but not between modules. QTL overlap predicts phenotypic correlations, and QTLs affecting the same trait module are significantly physically clustered in the genome. The genetic architecture of the selfing syndrome varies across systems, but the pattern of stronger within- than between-module correlation is widespread.

- Conclusions The genetic architecture we observe in the selfing syndrome is consistent with a growing understanding of floral morphological integration achieved via pleiotropy in clustered traits. This view of floral evolution is consistent with resource limitation or predation driving the evolution of the selfing syndrome, but invites further research into both the selective causes of 

mating system.

\section{INTRODUCTION}

25 The transition from outcrossing to selfing has occurred repeatedly in angiosperms (Barrett, 2002), and is

26 often associated with additional trait changes beyond the shift in mating system. Self-pollinating species

27 generally produce smaller flowers than outcrossing relatives, often with reduced color, nectar, pollen,

28 and scent. They also frequently differ from outcrossing relatives in non-floral traits, including

29 inflorescence structure and phenology. By analogy with biotic pollination syndromes, these changes are

30 collectively termed the "selfing syndrome" (Ornduff, 1969; Sicard and Lenhard, 2011; Woźniak and

31 Sicard, 2018).

32 Unlike biotic pollination syndromes, the selfing syndrome does not evolve in response to an obvious agent of selection. Nevertheless, there are reasons to believe that selection drives its evolution.

34 Repeated convergent evolution is itself often taken as evidence of repeated responses to similar

35 selective pressures (Stern, 2013). In addition, Qst-Fst studies (Duncan and Rausher, 2013a; Rifkin, Liao,

36 et al., 2019) and molecular analyses (Tsuchimatsu et al., 2020) indicate that at least some selfing-

37 syndrome traits have evolved in response to natural selection. However, for most selfing syndrome

38 traits, no such evidence exists.

39 There are three possible explanations for the evolution of these traits. They may have been favored by

40 selection acting directly on them. Alternatively, they may have evolved through a correlated response to

41 selection on other, genetically correlated traits. Finally, genetic drift could be largely responsible for

42 their evolution. These explanations are not necessarily independent or mutually exclusive. The degree of

43 trait correlation also shapes the way selection can effect trait change: when traits are uncorrelated,

44 adaptive change requires selection to act on each trait individually, but if several traits are positively 
correlated, selection on just one of them can cause all of them to change in the same direction.

Determining the degree to which selfing syndrome traits are genetically independent thus informs us about the nature of selection required to produce the syndrome.

Correlated evolution is a plausible explanation for selfing-syndrome changes. Floral traits often evolve in a strikingly coordinated fashion, likely due to pleiotropic effects of substitutions in loci underlying selected traits (Smith, 2015; Wessinger and Hileman, 2016). Theory predicts that trait correlations can

51 either facilitate or impede evolutionary change (Lande and Arnold, 1983), and experimental evolution

52 studies of selfing syndrome traits suggest facilitation may be common. For example, selection for smaller flowers in Eichornia paniculata (Worley and Barrett, 2000) also reduces nectar production, and

54 in Phlox selection on corolla size produces correlated changes in tube length and anther-stigma

55 separation (Lendvai and Levin, 2003).

QTL studies of the selfing syndrome also tend to support this pattern of trait correlation, but reveal wide

57 variation in genetic architecture across systems. At one extreme, QTLs affecting traits included in the selfing syndrome of Capsella rubella (Sicard et al., 2011; Slotte et al., 2012) are highly overlapping and localized to few regions of the genome. At the opposite extreme, the selfing syndrome of Mimulus is controlled by numerous loci that, although highly overlapping, are scattered widely across the genome

61 (Lin and Ritland, 1997; Fishman et al., 2002, 2014). In Solanum, both the number of regions and the

62 degree of overlap are low (Bernacchi and Tanksley, 1997; Georgiady et al., 2002). However, these

63 previous QTL studies have generally focused primarily on floral morphology and reproductive traits, and

64 have not consistently included the nectar, pollen, or phenological traits also typically associated with the 65 selfing syndrome. Consequently, the extent to which these traits are genetically independent of floral 
67 In this study, we examine these issues in the highly selfing Ipomoea lacunosa and its sister species, I.

68 cordatotriloba. Specifically, we examine the extent to which a broad array of selfing-syndrome traits,

69 including floral morphology, inflorescence structure, pollen traits, nectar production, and phenology,

70 have evolved in either an independent or a correlated manner in I. lacunosa. We apply two approaches.

71 First, we assess trait phenotypic correlations in an F2 population resulting from a cross between two

72 closely related species, one of which exhibits the selfing syndrome. Such correlations are expected to

73 reflect underlying levels of pleiotropy in loci involved in selfing syndrome evolution. We identify

74 evolutionary modules from these correlations. Second, we determine whether the co-localization of

75 quantitative trait loci (QTLs) for selfing-syndrome traits is consistent with pleiotropy. Specifically, we ask

76 whether QTL overlap is higher within modules than between modules, as would be expected for

77 independent evolutionary modules (Wagner and Altenberg, 1996; Brandon, 1999; Armbruster et al.,

78 2014). We then consider whether results of the two approaches provide a consistent picture of the

79 genetic architecture of divergence for the selfing syndrome.

80 The genetic architecture of divergence also offers insight into which selective forces likely shaped the

81 selfing syndrome of a given species. Different selective explanations for the evolution of the selfing

82 assume different amounts of correlation between traits (Sicard and Lenhard, 2011), with some requiring

83 high correlation and others allowing independent trait evolution. We apply our findings about the

84 degree of overlap in I. lacunosa to infer which possible selective causes were likely at play in the

85 divergence of these species. Finally, we place our results in the context of selfing syndrome evolution in

86 angiosperms more generally by performing a quantitative review of QTL overlap in studies of the selfing

87 syndrome. Specifically, we ask how genetic architecture, reflected in patterns of overlap, varies among

88 taxa. These general trends offer the opportunity for inferences about which selective factors most

89 frequently drive the evolution of the selfing syndrome. 


\section{METHODS}

\section{Study system}

93 Ipomoea lacunosa and I. cordatotriloba are weeds in series Batatas of the Convolvulaceae. They occur in

94 overlapping ranges in the southeastern United States (USDA and NRCS, 2017). Ipomoea lacunosa

extends north and east as far as Canada, and I. cordatotriloba extends south and west to Mexico.

Ipomoea lacunosa is highly selfing (>0.95), while I. cordatotriloba has a mixed mating system with highly selfing, highly outcrossing, and intermediate populations (Duncan and Rausher, 2013b). Although corolla size and in nectar production are due to selection (Duncan and Rausher, 2013a; Rifkin, Liao, et

\section{Generation of mapping population}

107 We generated a mapping population from seeds collected from a wild I. lacunosa population in Kinston, 108 North Carolina (lat. 35.23971, long. -77.57392) and a wild I. cordatotriloba population in Conway, South 109 Carolina (lat. 33.94713, long. -79.01940) (Duncan and Rausher, 2013a). Wild individuals were inbred for

110 four generations to develop our lab strains LPR ("Lacunosa ProTruck") and CAA ("Cordatotriloba Double-

111 A Lane"). The I. cordatotriloba population is sympatric with I. lacunosa and shows evidence of

112 substantial introgression from that species (Rifkin, Castillo, et al., 2019), although this was unknown at

113 the time these individuals were chosen. Despite this introgression, traits differ substantially between 
114 individuals of the two species used in our crosses (Table 1; (Rifkin, Castillo, et al., 2019; Rifkin, Liao, et

115 al., 2019)). Crosses were performed between clones of these individuals by emasculating I.

116 cordatotriloba buds and pollinating with whole I. lacunosa flowers. We generated seven F1 individuals

117 from this cross, cloned them via cuttings, and allowed them to self to generate F2 seeds. 508 F2 seeds

118 from a single F1 individual (“CL5”) formed our mapping population.

119 Plants were germinated in the spring of 2014 and flowered from July 2014 through early spring of 2015.

120 We scarified seeds and germinated them on filter paper in petri dishes in the dark. Seeds that had not

121 swelled within two days were re-scarified. Germinated seeds were transferred to individual 4" plastic

122 pots filled with Fafard 4P soil and grown in 16-hour days in a growth room for six weeks at $80^{\circ} \mathrm{F}$. The

123 light cycle was changed to 13 hours of light and a temperature of $65^{\circ} \mathrm{F}$ for two weeks to induce

124 flowering, after which plants were transferred to the Duke Research Greenhouse and maintained there 125 under greenhouse conditions.

\section{Phenotyping and trait modules}

\section{Phenology traits}

128 The selfing syndrome may include phenological and life-history as well as floral traits (Snell and Aarssen,

129 2005), and I. lacunosa exhibits faster early growth than I. cordatotriloba (Rifkin, Liao, et al., 2019). We

130 measured eight early growth traits (days to opening of first three leaves: L1, L2, L3; total height on day

13121 with the vine unwound to its full length: $\mathrm{H}$; number of leaves on day 21: NL; length of first three

132 internodes on day 21: INT1, INT2, INT3) and three floral phenology traits (average floral measurement

133 date: FD; whether any flowers were produced: EF; total number of flowers measured: NF) in 424 F2

134 hybrids (see Table 1). EF and NF were included in analyses because we observed considerable variation

135 in both traits: during the study period, some plants produced no flowers, while others flowered

136 continuously. Although we generally stopped measuring after 5 flowers had been sampled, we believe 
these measurements offer a proxy for genetic variation in the mapping population reflecting divergence in phenology between the two species. We measured early growth traits in selfed offspring of the grandparents of the mapping population in the same growout as the F2 hybrids ( $\mathrm{N}=46$ I. lacunosa, $47 \mathrm{I}$. cordatotriloba) but did not measure floral phenotypes in these plants because of space constraints.

141 These traits were also measured in F1 hybrids and in the selfed offspring of the grandparents of the 142 mapping population in a separate growout in the summer of 2013 ( $N=58 I$. lacunosa, 58 I. cordatotriloba, 13 F1). Measurements were consistent between these growouts, with the exception of

144 number of leaves, which was measured on day 23 rather than day 21 in the 2013 growout.

145 We measured total height and internode length with a rule and scored leaf opening as the time when 146 the focal leaf unfolded to an angle of greater than $90^{\circ}$. Floral phenology (FD) was scored as average

147 flower measurement date rather than days to first flower because the fast-growing vines required 148 frequent pruning and the first flower measured was not necessarily the first flower produced but plants 149 were measured soon after they began flowering. Because only a subset of the F2 individuals ever

150 flowered, we scored whether a plant ever produced flowers as a binary trait. Of the 507 seeds that 151 germinated, 424 survived transplant and were included in downstream analyses.

\section{Floral and inflorescence traits}

153 We measured flowers between 9:00 and 12:00 every morning. Only one flower was measured per

154 individual per day. Because flowers last for only a single day, flower age is unlikely to affect our

155 measurements. Floral traits were measured simultaneously in clones of each grandparent and the F1 156 parent of the mapping population. We thus had simultaneous floral measurements from only a single 157 genotype for grandparent and F1 floral traits. 
160

161

162

163

164

165

166

167

168

169

170

171 into modules. First, we identified modules using cluster analysis. Second, for comparison with previous

172 studies and with the clustering-based analyses, we grouped them into anatomical modules based on

173 organ or tissue type. The anatomically based modules we used were floral morphology, inflorescence,

174 nectar, pollen, and phenology. We chose these groupings because all of them, with the exception of

175 nectar, included multiple traits that are likely to be under selection in the same context, and some of

176 them have been previously shown to also reflect genetically correlated groupings in other systems

177 (Smith, 2015).

178 Our cluster analysis relied on the definition of a trait module as a group of traits that are highly

179 genetically correlated with each other but have low genetic correlations with traits in other modules

180 (Wagner and Altenberg, 1996; Brandon, 1999; Armbruster et al., 2014). In the context of trait

181 divergence between species, a trait module is a group of traits that are highly genetically correlated in

182 an F2 mapping population but show little correlation with traits in other modules. A module thus 
reflects divergent genes with pleiotropic effects that affect primarily traits in a single module. To the extent that phenotypic correlations in a mapping population reflect underlying genetic correlations, modules can be identified using cluster analysis on phenotypic correlations (Cheverud, 1988; Roff, 1995; Waitt and Levin, 1998; Feng et al., 2019).

For our cluster analysis, we used all measured traits in our F2 mapping population (Table 1) except color.

The correlation matrix was first converted to a distance matrix by the transformation $D_{i j}=1-r_{i j}{ }^{2}$, where

194 If modules have been correctly identified, we expect average correlations between traits within modules 195 to be larger than the average correlations between traits in different modules. To evaluate this 196 expectation, we calculated the average within- and between-module correlation (and their standard

197 errors) for each module. We also used a permutation test (1,000 replicate permutations), in which we 198 permuted which correlations were assigned to which trait pairs, to evaluate whether the average 199 within-module correlation (averaged over all modules) was greater than the average between-module 200 correlation (averaged over all module pairs). These analyses were performed by an APL program written by MDR (all APL programs available at https://github.com/joannarifkin/Ipomoea_QTL/tree/main/APL_scripts).

\section{Linkage map construction}

204 We generated markers from our mapping population using double-digest restriction-site associated DNA 205 sequencing (ddRADseq; Peterson et al., 2012) and sequenced them using the Illumina HiSeq platform 
206 (see Appendix S2 for details of extraction, restriction enzyme digest, barcoding, amplification, and

207 sequencing). After controlling for contamination, we ultimately included 396 F2 individuals in our

208 linkage map and subsequent QTL analysis. A linkage map was constructed using Lep-Map3 (Rastas et al.,

209 2013) from reads aligned to the I. lacunosa draft assembly (see Appendix S3 for details). We then used

210 Lep-Anchor (Rastas, 2020) to relate our linkage map to our draft assembly and generate marker orders

211 that incorporated the physical and linkage estimates, and a custom Python script to convert marker

212 names to positions on chromosomes. The final map included 6124 markers in 15 linkage groups. Scripts

213 are available on Github (https://github.com/joannarifkin/Ipomoea_QTL).

\section{QTL mapping}

215 We generated genotype data for QTL mapping using Lep-Map3's map2genotypes function and used

216 custom scripts to identify grandparent genotypes from the raw Lep-Map3 genotypes. Single-QTL

217 analyses were performed in QTL2 (Broman et al., 2019). Traits that were normally distributed or binary

218 were kept unchanged, while traits with highly skewed distributions were transformed and in some cases

219 split; see Appendix S4 for details. After splitting and transformation, we identified QTLs for a total of 27

220 phenotypes in 396 phenotyped and genotyped individuals (Table 1, Appendix S5). To identify QTLs, we

221 used the scan1 function in QTL2 with either the default or binary model (see Appendix S5 for details).

222 We determined significance cutoffs using permutation analysis (1000 replicates) at both genome-wide

223 and chromosome-wide levels. Confidence intervals were estimated as 1.5-LOD intervals. Additive and

224 dominance effects were estimated using the scan1coef function in QTL2. QTLs were categorized as over-

225 or under-dominant if the heterozygote value was outside of the range of the homozygote values. Scripts

226 are available on Github (https://github.com/joannarifkin/Ipomoea_QTL). 


\section{QTL overlap}

228 To quantitatively describe the genetic architecture underlying the selfing syndrome, we examined the 229 degree to which QTLs for different traits co-localized, and thus are potentially represented by the same 230 underlying genetic variant. A pair of QTLs was considered to co-localize if they had overlapping 1.5 LOD 231 confidence intervals. As an indicator of average overlap for a pair of traits, we used the Jaccard Index: J = $232 \quad \mathrm{I} /(\mathrm{A}+\mathrm{B}-\mathrm{I})$, where $\mathrm{I}=$ number of co-localizing QTLs, $\mathrm{A}$ is the total number of $\mathrm{QTLs}$ for the first trait, and

233 B is the total number of QTLs for the second trait. Average within- and between-module QTL overlap 234 (and standard errors) were calculated in an APL program written by MDR. To determine whether within235 module average overlaps and between-module average overlaps differed significantly, we performed a 236 permutation test (1,000 replicates) in which the QTLs were randomized with respect to traits. We 237 performed these analyses separately for QTLs that were significant only genome-wide and QTLs that 238 were significant both genome- and chromosome-wide.

239 We also performed an analysis to determine whether QTLs within modules are significantly 240 concentrated spatially compared to random placement of QTLs, as would be expected if QTL overlap 241 indicates pleiotropy. For traits within a module, we randomized the position of QTLs by weighting 50-kb 242 bins along chromosomes by the number of genes within those bins then choosing randomly among the 243 weighted bins. We identified genes using a newly generated annotation (Appendix S6). The position of 244 the QTL within the selected bin was chosen randomly. The size of each repositioned QTL was

245 maintained, only its position was changed. Once all QTLs associated with a module were positioned, we 246 calculated the average QTL overlap across module trait pairs as described above. This randomization

247 process was repeated 1,000 times to determine the proportion of average QTL overlap values greater 248 than the observed value. In addition to performing this analysis on each module separately, we also 249 performed an analogous analysis for the overall average QTL overlap for all within-module trait pairs. 
250 These analyses were performed using APL scripts written by MDR (available on Github:

251 https://github.com/joannarifkin/Ipomoea_QTL).

252 To determine whether patterns identified in our analysis of trait correlations were consistent with those

253 identified by our QTL analysis, we performed two types of analysis, each using either all QTLs or only

254 GWS QTLs. The first analysis asked whether phenotypic correlations between trait pairs were correlated

255 with Jaccard indices of overlap. Significance was evaluated by permuting the phenotypic correlation

2561,000 times. In the second analysis, we asked whether phenotypic correlations were correlated with

257 predicted genetic correlations, where genetic correlations were predicted from QTL properties following

258 a modified version of the approach of Gardner and Latta (2007). Significance was evaluated by

259 permuting QTLs among traits (see Appendix S7).

\section{QTL overlap review}

261 To compare our results to previous studies that examined the genetic architecture of the selfing

262 syndrome, we identified appropriate studies from reviews of genetic architecture of floral changes and

263 from the search terms "selfing syndrome" and "QTL" on Google Scholar, Web of Science, and ProQuest.

264 For each study, we extracted all QTLs as a table and calculated the Jaccard Index of overlap for all trait

265 pairs. We then categorized traits into the following trait modules: floral morphology, nectar,

266 inflorescence structure, phenology, pollen, reproductive, or vegetative. Reproductive traits, which were

267 not included in our QTL study, consisted of seed number, fruit, and compatibility traits. We also treated

268 herkogamy as a reproductive trait. We selected these categories because QTL studies of floral trait

269 evolution generally suggest that these groupings reflect biological realities and to facilitate comparison

270 with our anatomical modules (Ashman and Majetic, 2006; Smith, 2015; Feng et al., 2019). 


\section{RESULTS}

\section{Phenotypic distributions}

273 The parents of our mapping population reflected known differences in selfing-syndrome traits between

274 Ipomoea lacunosa and I. cordatotriloba ((Rifkin, Liao, et al., 2019), Table 1). However, both parents

275 exhibited similarly low herkogamy, perhaps because the I. cordatotriloba parent of the mapping

276 population was collected from a population sympatric with I. lacunosa; we therefore did not include

277 herkogamy in subsequent analyses. In the F1 and F2 offspring, we observed a general tendency towards

278 I. cordatotriloba dominance in floral traits and I. lacunosa dominance in phenological traits (Table 1).

279 Finally, color is known to be under single-locus control in I. lacunosa (Duncan and Rausher, 2020) and, 280 consistent with this, F2s produced purple and white flowers in a ratio that did not differ from 3:1 $\left(\chi^{2}=\right.$

$2813.8352, \mathrm{P}=0.0501)$.

282 Modules identified by cluster analysis

283 There was substantial variation in the magnitude of the F2 phenotypic correlations, which ranged from 0 284 to 0.965 . Half of the correlations (115) were negative, while the other half (116) were positive (Appendix 285 S4, Appendix S8, Appendix S9). Based on these correlations, the three cluster algorithms used generally 286 produced a consistent set of modules (Table 1; Appendix S10), which were broadly similar to the 287 anatomical modules of floral morphology, phenology, inflorescence traits, nectar, and pollen. This 288 suggests that in the absence of more complete genetic or phenotypic data, anatomical groupings reflect 289 underlying genetic groupings. Module 1 consists of all floral dimension traits and nectar volume. Module 2902 includes both inflorescence traits and the phenological trait of flowering date. Module 3 consists of a 291 subset of phenological traits (all internode lengths). Pollen traits cluster in module 4, along with the 292 phenological trait flowers per day. Finally, module 5 consists of the remaining phenological traits (dates 293 of leaf emergence, number of leaves on day 21, height on day 21). 
294 Three traits clustered in different modules across the three clustering algorithms: nectar volume

295 clustered in module 1 in two analyses and in module 2 in one; flowers per day clustered with module 4

296 in two analyses and alone in one analysis; and herkogamy clustered with module 4 in one analysis and

297 alone in two analyses. In subsequent analyses, we grouped traits in whichever module most frequently

298 included them.

\section{Correlations within and between modules}

300 Average trait correlations within a module are substantially higher than average trait correlations

301 between modules (Table 2). Within-module correlations averaged 0.509, almost five times higher than 302 between-module correlations (0.105; $\mathrm{P}<0.001$, permutation test).

303 Nectar volume has a lower average correlation with other traits in module $1(0.314$, standard error $=$ $0.041)$ than the average correlation among those traits $(0.440$, s.e. $=0.076)$, suggesting that nectar

305 volume may not actually belong to module 1. However, this trait exhibits high correlations with corolla 306 tissue length and corolla width ( 0.451 and 0.423 , respectively), which are approximately equal to the 307 average within-module correlation for module 1. Moreover, the average correlation of nectar volume 308 with other module 1 traits is approximately equal to that of LW and TLL with other module 1 traits 309 (0.347 and 0.313, respectively). On balance, therefore, we believe that the evidenced for removing 310 nectar volume from module 1 is weak. Within-module correlations were strongest for modules 2 and 3.

311 One measure of pollen number was positively correlated with pollen size; this suggests that rather than 312 experiencing a size-number tradeoff, l. cordatotriloba invests more in pollen in multiple ways, as has 313 also been shown for nectar in this species (Rifkin, Liao, et al., 2019).

314 With the exception of flower measurement date, which was negatively correlated with inflorescence, 315 flower size, and nectar traits, we found almost no significant correlations between phenology and floral 316 traits. 
317 Linkage map

318 We initially placed 6530 markers on 19 linkage groups, including fifteen large groups taken to

319 correspond to the 15 chromosomes in the I. lacunosa karyotype (Nakajima, 1963). We used this map to

320 assign the positions of 49 of the 50 scaffolds in our draft genome assembly to 15 linkage groups. We

321 then reordered the markers according the physical order, removed markers that caused large gaps, and

322 joined two small linkage groups to large linkage groups based on draft assembly physical order. Our final

323 map consisted of 6124 markers on 15 LGs of between 174 and 627 markers each, with a total map

324 length of $2222.8 \mathrm{~cm}$ and LGs averaging $148.19 \mathrm{~cm}$.

325 Overall, the linkage map is consistent with the known karyotype of I. lacunosa: we identified 15 linkage

326 groups, consistent with the 15 chromosomes. We also tested for segregation distortion in the

327 completed map. 581 markers (9\%) displayed significant segregation distortion following a Bonferroni

328 correction. Distorted markers were concentrated on LGs 3 (117 distorted markers), 10 (126 distorted

329 markers), 11 (176 distorted markers), and 15 (116 distorted markers).

\section{QTL mapping and effect sizes}

331 We identified 50 QTLs that were significant genome-wide (GWS), and an additional 101 that were

332 significant only at the chromosome level (CWS; Fig. 1A, B, Appendix S4). QTLs were widely scattered

333 across the linkage groups, with 4-12 CWS and 1-8 GWS QTLs per chromosome.

334 Because we believe the CWS QTLs we identified are likely real (see Discussion), we examined patterns of

335 Percent of Variation explained (PVE) and Relative Homozygous Effect sizes (RHE) for all detected QTLs.

336 Both total PVE and total RHE varied substantially across traits (Appendix S11).

337 Modules differed in average effect sizes of the QTLs associated with them (Appendix S4, Appendix S12).

338 In general, floral morphology and nectar volume, which clustered together as module 1, had QTLs of

339 relatively small effect (floral morphology mean RHE 0.093, maximum RHE 0.288; nectar volume mean 
RHE 0.061, maximum RHE 0.082). Between-species differences in these traits thus reflect the accumulation of numerous small-effect QTLs. By contrast, between-species differences in the lifehistory, pollen, and inflorescence traits that clustered in traits of modules 2, 4, and 5 (internode lengths, pollen traits, and inflorescence size, respectively) were on average caused by QTLs with moderate effect

344 sizes (mean and maximum RHE $>0.1$ and $<0.5$ ), while the subset of phenology traits that clustered in 345 module 3 were caused by substitutions of alleles with large effect (mean and maximum RHE $>0.5$ ). In

346 fact, many of these QTLs had RHE > 1.0, which means individually they caused a change in the trait

347 larger than the final difference between species. The sum of the signed RHE for a trait (TRHE, Appendix 348 S11) indicates how well the detected QTLs explain the species difference in that trait. Excluding L1 and

349 L2, which had strongly negative TRHE values, the average proportion of parental difference explained was 0.42 . Thus while a substantial number of QTL were identified, there must be undetected QTLs, presumably of smaller effect, that account for a little more than half of the observed differences

352 between the two parents.

353 For both GWS QTLs and CWS QTLs, the number of QTLs that had effects in the same direction as the 354 species difference (consistent-directional QTLs) was substantially larger than the number having effects 355 in the opposite direction as the species difference (contra-directional QTLs; Appendix S4, Appendix S13), 356 consistent with selection operating to fix many of these substitutions. The proportion of QTLs with 357 consistent-directional effects was not statistically different for the two sets of QTLs (Appendix S13). 358 Module 1 traits in particular (excluding style length) show high proportions of consistent-directional 359 QTLs (0.95, 0.80 and 0.89 for GWS, CWS and All QTLs, respectively; Appendix S13). By contrast, for style 360 length, the corresponding proportions are only $0.5,0.25$ and 0.4. Traits in other modules exhibit 361 proportions that are considerably lower $(0.5,0.79$, and 0.66$)$ than for module 1 traits excluding style 362 length. 


\section{QTL overlap and predicted genetic correlations}

364 QTL overlap is substantially higher within modules than between modules. Mean overlap for all traits was 0.166 for all QTL and 0.114 for GWS QTLs with genome-wide significance. For only QTLs with genome-wide significance, within-module average overlap (0.320) was significantly higher than between-module average overlap (0.037; $\mathrm{P}<0.001$, permutation test; Table 3A). An analysis using all QTLs showed similar results (Table 3B; within- and between-module average overlaps 0.320 and 0.056 , respectively; $\mathrm{P}<0.001)$. These analyses show that within-module overlap was at least 6 times greater than between-module overlap, indicating almost complete genetic independence of the modules.

371 Randomly reshuffling QTL spatial positions throughout the genome suggests that QTLs within a module

372 are significantly clustered spatially within the genome, as has been observed in other systems (Salih and

373 Adelson, 2009; Kostyun et al., 2019). Using all QTLs, for each of the five modules, as well as for all

374 modules pooled, the probability of obtaining the observed average within-module QTL overlap by

375 random placement of QTLs in the genome was less than 0.001 (Table S5). With only GWS QTLs, modules

3761 and 5 , as well as the pooled average were also highly significant $(P<0.001)$, while module 3 was not

377 significant $(P=0.066)$ and modules 2 and 4 could not be evaluated because they had QTLs for only 1

378 trait.

379 Both this analysis and that of the F2 character correlations produce similar patterns of high within-

380 module integration and low between-module integration. We quantified this similarity in two ways.

381 First, we calculated the correlation between pairwise trait correlations and pairwise QTL overlap. For all

382 QTLs, this correlation was moderately high $(0.64 ; \mathrm{P}<0.001)$, whereas for only GWS QTLs, there was little 383 correlation (0.046) (Fig. 2A, B). Second, we examined the correlation of average trait correlations with 384 QTL overlap over all module pairs (including a module paired with itself). Using all QTLs, this correlation 385 is high (0.717) and significant $(P=0.005$, permutation test), whereas with only GWS QTLs, the 
correlation is low and non-significant by a permutation test (Fig. 2C). This concordance of the two measures of integration suggests that both the F2 character correlations and the QTL overlap patterns reflect the same underlying genetic architecture of distinct modules, at least when all QTLs are considered.

Comparing the predicted genetic correlations with the observed phenotypic correlations suggests that our observed QTL overlaps captured the genetic architecture moderately effectively, as has been observed in QTL studies of other systems (Gardner and Latta, 2007). For all QTLs, the correlation between the predicted genetic correlation and the observed phenotypic correlation was 0.516 , and for GWS QTLs only it was 0.546 (Fig. 3). Removing trait pairs predicted to have no genetic correlation (i.e., trait pairs with no overlapping QTLs) increased the strength of the correlations slightly to 0.554 and 0.582. All correlations are highly significant $(P<0.001$, Permutation test $)$. Using pairwise module averages produced a similar result, with a moderate correlation using all QTLs $(r=0.621, P=0.011)$ and a slightly smaller correlation using only GWS QTLs ( $r=0.437, P=0.066$; Fig. 3E, F).

Bias, measured as the difference between the predicted genetic correlation and observed phenotypic correlation, increased with the absolute value (magnitude) of phenotypic correlations (Appendix S15),

401 suggesting that for pairs of traits with large phenotypic correlations unidentified QTLs may contribute to 402 those correlations. However, bias was uncorrelated with either average total percent of variance explained or total relative homozygous effect (Appendix S15, Appendix S16), which are indicators of the

404 completeness of QTL identification.

\section{QTL overlap in other selfing-syndrome species}

406 Our results suggest that trait change within modules may have been correlated in the evolution of the 407 selfing syndrome of I. lacunosa, but that between-module correlation likely did not play a major role in 
selfing syndrome, we applied our measure of QTL overlap to published QTL studies of the selfing

412 pollination syndromes likely varies between systems (Smith, 2015), anatomical groupings offer the

413 advantage that they can be applied broadly across systems even when other approaches to grouping

414 traits are not available.

415 Generally, patterns exhibited by the anatomical modules in our study are similar to those for the cluster

416 modules, which supports the usefulness of anatomical groupings when other approaches are

417 unavailable. Average trait correlations are substantially higher within modules than between modules

418 (Appendix S17). QTL overlap was substantially and significantly higher within modules than between

419 modules for both GWS and all QTLs (Appendix S18). The randomization test indicated that there is

420 significantly more QTL overlap within modules than expected by random placement of QTLs (Appendix

421 S19), although this test could not be performed for some modules because there were QTLs for only one

422 trait. The correlation across module pairs between average phenotypic correlation and average QTL

423 overlap was moderate (0.506) and significant for all QTLs, but weak (0.207) and non-significant for GWS

424 QTLs (Appendix S20).

425 For comparison, we identified nine published QTL mapping studies of the selfing syndrome. They

426 spanned a broad range of angiosperm model systems: three studies in Mimulus (Lin and Ritland, 1997;

427 Fishman et al., 2002, 2014), two from Solanum (Bernacchi and Tanksley, 1997; Georgiady et al., 2002),

428 three in Capsella (Sicard et al., 2011; Slotte et al., 2012; Woźniak et al., 2020), and one from Leptosiphon

429 (Goodwillie et al., 2006). We grouped traits from the previous publications into these same anatomical 
432 Appendix S21). We found similar degrees of overlap in the same and related species even though the

433 studies include spanned a wide range of time and methods.

434 Between-module overlap was lower (mean 0.180) than within-module overlap (mean 0.295) for all

435 systems where it could be calculated except Solanum, in which both studies found higher between- than

436 within-module overlap (between: 0.229, 0.5; within: 0.143, 0.167; Bernacchi and Tanksley 1997;

437 Georgiady et al. 2002). However, the level of both within- and between-module overlap varied widely

438 from very high overlap in one Capsella study (within: 0.643, between: 0.256; (Sicard et al., 2011)) to

439 fairly low overlap in Solanum (within: 0.143-0.167; between: 0-0.5; (Bernacchi and Tanksley, 1997;

440 Georgiady et al., 2002). This is consistent with highly variable importance of genetic correlations in the

441 evolution of different species' selfing syndromes.

442 The pattern within floral morphology also reflects this diversity. Floral morphology was examined in the

443 greatest number of studies, and both numbers of QTLs and degrees of overlap varied considerably

444 across systems. Mimulus exhibits variable overlap among many widely scattered QTLs $(0.144,0.343$,

445 0.366; (Lin and Ritland, 1997; Fishman, Kelly and Willis, 2002; Fishman et al., 2014). In Solanum, the

446 degree of overlap and number of regions in play are lower (0.234, 0.167; (Bernacchi and Tanksley, 1997;

447 Georgiady et al., 2002). In Leptosiphon, overlap is quite high (0.301; (Goodwillie et al., 2006), and studies

448 in Capsella find high concentration of floral morphological traits into few regions $(0.286,277,0.369$,

449 0.367; (Sicard et al., 2011; Slotte et al., 2012; Woźniak et al., 2020). Therefore the pattern we observed

450 in Ipomoea lacunosa floral traits, of numerous loci of small effect with high overlap, is common but by

451 no means universal, and the floral reductions of the selfing syndrome can evolve from a variety of

452 underlying genetic architectures.

453 Finally, we identified considerable variation in which pairs of modules showed the strongest overlap. In

454 Capsella, vegetative traits frequently showed high overlap with floral morphological and reproductive 
traits (Sicard et al., 2011; Woźniak et al., 2020), which appears to be unusual in flowering plants

456 (Ashman and Majetic, 2006; Feng et al., 2019). In Mimulus and Solanum, floral morphological traits and

457 inflorescence traits overlapped more (Georgiady et al., 2002; Fishman et al., 2014). In Ipomoea, the

458 strongest overlaps were between nectar volume and floral morphology; although this has not been

459 examined in other selfing-syndrome systems, overlapping QTLs have been observed for floral

460 morphology and nectar traits in Penstemon, Petunia, and Mimulus (reviewed in (Smith, 2015)). Overall,

461 Ipomoea fell on the low end of QTL overlap both within and between modules. This study is the first to

462 quantify the diversity of genetic architectures underlying convergently evolved selfing syndromes, and

463 indicates a plethora of possible routes to the same pollination syndrome.

\section{DISCUSSION}

465

466

467

468

469

470

471

472

473

474

475

476

477

\section{Architecture of evolutionary divergence}

Although the selfing syndrome has evolved repeatedly in angiosperms, the role of correlated evolution, the relative contributions of selection and drift, and what agents of selection act all remain unclear. Ipomoea lacunosa is an effective system to explore these problems because selection is implicated in the divergence of at least a subset of its selfing-syndrome traits (Duncan and Rausher, 2013a, 2020; Rifkin, Liao, et al., 2019). Ipomoea lacunosa and its mixed-mating sister species l. cordatotriloba hybridize in nature, with substantial asymmetric introgression from I. lacunosa into I. cordatotriloba (Rifkin, Castillo, et al., 2019; average proportion admixture from I. lacunosa >0.5). Nevertheless, I. cordatotriloba sympatric with I. lacunosa retain considerable, but not complete, genetic and phenotypic divergence in selfing-syndrome traits, which suggests ongoing divergent selection on these traits. Consequently, the genetic architecture of divergence described here does not reflect the full range of divergence between allopatric populations of the two species. Nevertheless, our results provide insight into the degree to which different components of the selfing syndrome have evolved independently. 
478 If the selfing syndrome of I. lacunosa results largely from correlated evolution, we predict high QTL

479 overlap and strongly genetically linked traits. If, on the other hand, selfing-syndrome traits evolved

480 through independent selection on independent traits, we predict low overlap. In our mapping

481 population, both F2 correlation and QTL overlap patterns revealed distinct modules that largely overlap

482 anatomical categories. Traits within modules are moderately to highly correlated and exhibit moderate

483 to high QTL overlap, and within-module trait correlations are overwhelmingly positive. These patterns

484 suggest correlated divergence of traits within modules. By contrast, between-module trait correlations

485 are generally low, as is QTL overlap between traits from different modules. Together, these findings

486 indicate that modules were able to diverge independently, possibly at different times and due to

487 different selective pressures.

488 A consistent aspect of the selfing syndrome across many species is a reduction in multiple floral

489 characters, including size, pollen production, and nectar production (Sicard and Lenhard, 2011). This can

490 be explained either through a general pattern of high genetic correlation among floral traits, or by

491 independent selection on independent traits. For example, the evolution of reduced floral traits could

492 result from selection to shorten development time, leading to a reduced number of cell divisions (Krizek

493 and Anderson, 2013) that affects all floral traits similarly. In this situation, selection acting directly on

494 only a subset of floral traits could cause a correlated reduction of all floral traits. In I. lacunosa, we

495 identified at least two genetically distinct floral modules: one consisting of size traits and probably

496 nectar production, and one consisting of pollen traits. Previous experiments have demonstrated that

497 natural selection contributed to floral size divergence (Rifkin, Liao, et al., 2019), so reductions in floral

498 dimensions likely evolved in a correlated fashion, but the genetic independence of floral dimensions and

499 pollen characters indicates that reduction in pollen production was not a correlated response to

500 selection for floral size reduction. Whether reduced pollen production was caused by directional

501 selection or by reduced purifying selection coupled with genetic drift is unclear; our previous study 
502 failed to detect any evidence for selection having favored reduce pollen production in I. lacunosa, but

503 evidence from Arabidopsis thaliana, another selfing species, implicates selection in pollen reduction

504 (Rifkin, Liao, et al., 2019; Tsuchimatsu et al., 2020).

505 Although a correlated response to selection can explain the evolution of the floral traits in module 1, the 506 reduction in style length may be an exception. Of the 10 QTL we identified for this trait, six were contra-

507 directional (Appendix S13). However, because only one of these overlapped any other floral QTLs, it

508 seems unlikely that I. Iacunosa alleles at these loci were fixed because they had advantageous

509 pleiotropic effects on other floral characters. Instead, it seems possible that genetic drift played a

510 substantial role in style reduction despite any correlated response to selection on other floral traits. An

511 alternative explanation that we cannot rule out, however, is that the contra-directional QTL alleles fixed

512 in I. lacunosa represent compensatory corrections for correlated responses dragging style length beyond

513 its optimum.

514 Between-module correlations were generally weaker than within-module correlations, but may also play

515 a role in divergence. For example, cyme length is also diverged between species, but a role for selection

516 has not been identified (Rifkin, Liao, et al., 2019). Although in a distinct module, cyme length is

517 somewhat correlated with floral morphology. Therefore, indirect selection through shared loci that

518 affect floral traits may have caused cyme lengths to diverge in the absence of selection.

519 In addition to reductions in floral traits, highly selfing species often exhibit changes in vegetative traits,

520 including early growth rate, perhaps because highly selfing species are often found in marginal habitats

521 where rapid growth is at a premium (Snell and Aarssen, 2005). We have previously shown that changes

522 in these types of traits have occurred in I. lacunosa (Rifkin, Liao, et al., 2019). Here we have

523 demonstrated that early growth traits are independent from floral traits and constitute two genetically

524 distinct evolutionary modules: one reflecting the rate of internode elongation, the other reflecting 
general plant size, as reflected in total plant height and number of leaves at day 21 , as well as the timing

526 of leaf production. If selection was responsible for these changes, it acted independently on at least two

527 aspects of early growth.

528 The overall picture that emerges from our study is that the I. lacunosa selfing syndrome has evolved 529 piecemeal through changes in at least five distinct groups of traits. Within these modules, correlated 530 responses to selection probably account for much of the change, although in some instances (e.g.

531 evolution of shorter styles) drift may have also played a role. Our interpretation of correlated selection

532 assumes that QTL overlap is indicative of pleiotropy of a single underlying causal variant. Instead, the 533 overlap may represent chance proximity of two different causal variants that were fixed sequentially.

534 Assuming that mutations in many genes scattered throughout the genome could affect a particular trait,

535 it seems unlikely that different variants affecting two traits would by chance be in physical proximity, 536 and likely that average overlap between QTLs affecting those two traits would be low. Our simulations 537 of random placement of QTLs bear this out for within-module trait pairs, and show that the actual 538 overlap is substantially higher than expected by chance placement. These results, as well as evidence of 539 within-module pleiotropy in other systems (Smith, 2015), lend support to the hypothesis that much of 540 the observed QTL overlap is due to pleiotropy.

541 The low degree of between-module correlation also allows inferences about which possible selective 542 pressures may have acted. Different selective explanations for the selfing syndrome depend on different 543 degrees of trait correlation (Sicard and Lenhard, 2011). Two proposed explanations depend on high 544 correlation: that selection to self-pollinate efficiently could lead to general reductions in floral traits, or 545 that selfing plants colonizing marginal environments experience selective pressure to mature and 546 reproduce faster in these marginal environments, leading to smaller flowers. Other possible 547 explanations impose no such requirement: the selfing syndrome may result from reallocation of 548 resources from pollinator attraction and pollen export to other functions that increase fitness, or selfing 
plants may reduce floral traits to avoid florivory by insects. The high degree of independence we found among I. lacunosa's selfing-syndrome traits is more consistent with these explanations, which allow traits to evolve independently rather than depending on correlation. Indeed, I. cordatotriloba experiences considerable damage from florivorous insects (Sowell and Wolfe, 2010).

\section{Consistency of approaches}

554 Evolutionary analyses of correlated suites of characters typically rely on inferences based on genetic correlation matrices (e.g. (Delph et al., 2010)). However, genetic correlations are determined by the extent to which QTLs underlying genetic variation have pleiotropic effects on multiple characters, and

557 QTL studies can also be used to both understand and predict genetic correlations (Kelly, 2009; Saltz et 558 al., 2017), although the consistency of these approaches is seldom evaluated. Our study provides evidence that QTL analyses and estimates of F2 correlations provide consistent pictures of the genetic architecture of evolutionary divergence. In particular, we found that evolutionary modules identified by

561 analysis of F2 trait correlations are consistent with patterns of QTL overlap: there is a high correlation

562 between between- and within-module F2 correlations, and average QTL overlaps between and within

563 modules. Additionally, QTL properties predict genetic correlations that exhibit a moderately high

564 correlation with the F2 correlations. These patterns are detectible even though our QTLs on average 565 explain only about 40 percent of the between-species differences.

566 One caveat to this conclusion is that we measured F2 phenotypic correlations rather than genetic

567 correlations. However, if environmental correlations are not large or not in a direction opposite to the

568 genetic correlations, phenotypic correlations should reflect the underlying genetic correlations (Falconer

569 and Mackay, 1996). Moreover, empirical analyses generally find concordance between genetic and

570 phenotypic correlations (Cheverud, 1988). We thus believe that the F2 phenotypic correlations we

571 measured likely reflect the underlying genetic correlations. 
572 In our study, we detected 43 QTLs with genome-wide significance for which data was available on the

573 direction of trait differences between species, and an additional 38 with just chromosome-wide

574 significance. Similar behavior between the GWS and CWS QTLs suggests that the CWS QTLs are general

575 rather than artifactual. The correlation between F2 correlations and QTL overlap (Fig. 2) is similar when

576 using all QTL rather than just GWS QTL. If the CWS QTLs were artifactual, we would expect that an

577 analysis including them would reduce the strength of the correlation. Similarly, the difference in average

578 pairwise QTL overlap between within- and between-module comparisons was similar for analyses using

579 all QTL and just GWS QTL. Again, if the CWS QTL were artifactual, we would expect that the difference

580 would be substantially reduced in the former analysis. We also observed that the direction of QTL

581 effects (in same or opposite direction as species difference) was highly biased against contra-directional

582 effects (Table S6), and the proportion of consistent- vs contra-directional effects was not statistically

583 different between GWS and CWS, with both types of QTL exhibiting significant bias toward QTL with

584 consistent-direction effects $(P<0.005$ in both cases). Artifactual QTLs should exhibit no bias in the

585 direction of effects. We believe these similarities between results with GWS and CWS QTLs justify

586 treating all QTLs as legitimate.

\section{Comparative genetic architecture of the selfing syndrome}

588 The selfing syndrome has evolved repeatedly in numerous angiosperm lineages. Our quantitative review

589 places the genetic architecture of the I. lacunosa selfing syndrome in a wider context of selfing

590 syndrome evolution. Across the studies we examined, we found QTL overlap to be highly variable, both

591 within and between modules. Floral traits, which have been studied most extensively, show a wide

592 range of variation for within-module overlap. In Mimulus, most studies find high QTL overlap within

593 floral traits (Lin and Ritland, 1997; Fishman et al., 2002, 2014), and that floral traits are controlled by

594 pleiotropic QTLs scattered across the genome. Overlap is high, but overall numbers of QTL lower, in

595 Leptosiphon and Capsella (Goodwillie et al., 2006; Sicard et al., 2011; Slotte et al., 2012; Woźniak et al., 
2020), while Solanum had low overlap for floral traits and few regions (Bernacchi and Tanksley, 1997;

597 Georgiady et al., 2002). Between-module overlap also varies widely across systems. In general, floral

598 traits are expected to be more interconnected with each other than with vegetative traits (Fenster and

599 Armbruster, 2004; Ashman and Majetic, 2006; Glover et al., 2015; Smith, 2015), and consistent with this,

600 we generally found higher within- than between-module overlaps. However, average between-module

601 overlap varied widely, and indeed, in the genus Solanum both flowering time (Bernacchi and Tanksley,

602 1997) and inflorescence structure (Georgiady et al., 2002) were so strongly correlated with floral traits

603 that between-module correlation was stronger than within-module correlation, and a clustering

604 approach to module identification would likely identify different underlying genetic groupings.

605 It is unlikely that genome structure alone drives this variation in genetic architecture. The species

606 included in these studies vary in genome size and number of chromosomes, but Ipomoea and Mimulus,

607 which have very different patterns of QTL overlap, are similar in genome size (M. guttatus, 430Mb; I.

608 lacunosa and $I$. cordatotriloba, 497Mb and 525Mb respectively) and chromosome number (M. guttatus,

$6092 \mathrm{~N}=28$, I. lacunosa and I. cordatotriloba, 2N=30) (Duncan and Rausher, 2013b; Institute, 2017). The

610 variation we noted in genetic architecture is also not explained by the number or type of traits included:

611 studies in the same systems are broadly similar across time, and there was extensive variation both in

612 studies that included floral and phenology traits and in studies that only included floral traits. This

613 variation in genetic architecture suggests that selective causes for the selfing syndrome may vary across

614 systems: in Ipomoea we can reject explanations for selfing-syndrome evolution that depend heavily on

615 genetic correlation, but they likely occur in other systems.

\section{Conclusions and future directions}

617 The research we describe here identifies two areas of high priority for future research in determining

618 how and why the selfing syndrome generally evolves. 
619 First, much remains unknown about the relative importance of the possible selective causes in selfing

620 syndrome evolution across angiosperms. It is possible to make specific evolutionary predictions based

621 on these selective explanations, but they must be tested with empirical data. For example, nectar

622 volume is unlikely to affect the efficiency of selfing, but may influence insect predators. Similarly, the

623 selfing syndrome can only evolve in response to selection for faster global development or as a

624 byproduct of selection for more efficient selfing in species with strong correlations between traits. We

625 predict that species with greater independence are more likely to evolve the selfing syndrome through

626 resource allocation or evading florivory. Field tests of selection in species with known genetic

627 architecture and natural history could evaluate these predictions.

628 The variation in genetic architecture also invites questions about how genetic architecture itself evolves

629 (Hansen, 2013). We generally found consistent genetic architecture within the same systems, but one

630 study has identified decreased floral trait integration in selfing species compared to outcrossing

631 relatives, so this pattern may be weaker in selfing species than in other pollination syndrome shifts

632 (Anderson and Busch, 2006). Further understanding the relationship between genetic architecture and

633 the transition to selfing is another priority moving forward in efforts to understand the relationship

634 between selection, drift, and genetic architecture in the evolution of the selfing syndrome.

635 ACKNOWLEDGMENTS

636 We thank Tanya Duncan for support in identifying populations and developing the mapping population,

637 and Shu-Mei Chang and Stephen DiMaria for assistance with pollen measurements. Funding was

638 provided by NSF grant DEB 1542387 to MDR, by NSF DDIG grant DEB 1501954 to JLR. 


\section{AUTHOR CONTRIBUTIONS}

640 JLR and MDR conceived the design, analyzed the data, and wrote the manuscript. JLR generated, grew,

641 and phenotyped the mapping population, constructed the genetic libraries, and performed the QTL

642 mapping and quantitative review. MDR performed the cluster analyses, comparison of predicted genetic

643 correlations with QTL overlap, and analysis of QTL clustering. GC performed the genome annotation and 644 calculated gene densities.

\section{DATA AVAILABILITY STATEMENT}

646 Raw sequencing reads from the F2 mapping population will be available on the SRA (PRJNA691909,

647 embargoed until publication). Scripts are available on Github

648 (https://github.com/joannarifkin/Ipomoea_QTL). 
650

651

652

653

654

655

656

657

658

659

660

661

662

663

664

665

666

667

668

669

670

\section{WORKS CITED}

Anderson, I., and J. Busch. 2006. Pollinator-mediated selection weakens floral integration in self-

compatible taxa of Leavenworthia (Brassicaceae). American Journal of Botany 93: 860-867.

Armbruster, W. S., C. Pélabon, G. H. Bolstad, and T. F. Hansen. 2014. Integrated phenotypes:

Understanding trait covariation in plants and animals. Philosophical Transactions of the Royal Society B: Biological Sciences 369.

Ashman, T.-L., and C. J. Majetic. 2006. Genetic constraints on floral evolution: a review and evaluation of patterns. Heredity 96: 343-352.

Barrett, S. C. 2002. The evolution of plant sexual diversity. Nature Reviews Genetics 3: 274-84.

Bernacchi, D., and S. Tanksley. 1997. An interspecific backcross of Lycopersicon esculentum x L. hirsutum: linkage analysis and a QTL study of sexual compatibility factors and floral traits. Genetics 14850: 861-877.

Brandon, R. N. 1999. The units of selection revisited: the modules of selection. Biology and Philosophy 14: $167-180$.

Broman, K. W., D. M. Gatti, P. Simecek, N. A. Furlotte, P. Prins, Ś. Sen, B. S. Yandell, and G. A. Churchill. 2019. R/qt|2: Software for mapping quantitative trait loci with high-dimensional data and multiparent populations. Genetics 211: 495-502.

Cheverud, J. M. 1988. A comparison of genetic and phenotypic correlations. Evolution 42: 958-968.

Delph, L. F., A. M. Arntz, C. Scotti-Saintagne, and I. Scotti. 2010. The genomic architecture of sexual dimorphism in the dioecious plant Silene latifolia. Evolution 64: 2873-2886.

Duncan, T. M., and M. D. Rausher. 2013a. Evolution of the selfing syndrome in Ipomoea. Frontiers in 
672 Duncan, T. M., and M. D. Rausher. 2013b. Morphological and genetic differentiation and reproductive isolation among closely related taxa in the Ipomoea series Batatas. American Journal of Botany 100: $2383-2193$.

675

676

677

678

679

680

681

682

683

684

Duncan, T. M., and M. D. Rausher. 2020. Selection favors loss of floral pigmentation in a highly selfing morning glory. PLOS ONE 15: 1-18.

Falconer, D. S., and T. F. C. Mackay. 1996. Introduction to quantitative genetics. Longman Group, Essex.

Feng, C., C. Feng, L. Yang, M. Kang, and M. D. Rausher. 2019. Genetic architecture of quantitative flower and leaf traits in a pair of sympatric sister species of Primulina. Heredity 122: 864-876.

Fenster, C., and W. Armbruster. 2004. Pollination syndromes and floral specialization. Annual Review of Ecology, Evolution, and Systematics 35: 375-403.

Fishman, L., P. M. Beardsley, A. Stathos, C. F. Williams, and J. P. Hill. 2014. The genetic architecture of traits associated with the evolution of self-pollination in Mimulus. The New Phytologist 205: 907917.

Fishman, L., A. J. Kelly, and J. H. Willis. 2002. Minor quantitative trait loci underlie floral traits associated with mating system divergence in Mimulus. Evolution 56: 2138-55.

Gardner, K. M., and R. G. Latta. 2007. Shared quantitative trait loci underlying the genetic correlation between continuous traits. Molecular Ecology 16: 4195-4209.

Georgiady, M., R. Whitkus, and E. Lord. 2002. Genetic analysis of traits distinguishing outcrossing and self-pollinating forms of currant tomato, Lycopersicon pimpinellifolium (Jusl.) Mill. Genetics 344: 333-344. 
692

693

694

695

696

697

698

699

700

701

702

703

704

705

706

707

708

709

710

711

Lande, R., and S. J. Arnold. 1983. The measurement of selection on correlated characters. Evolution 37:

Glover, B. J., C. A. Airoldi, S. F. Brockington, M. Fernández-Mazuecos, C. Martínez-Pérez, G. Mellers, E. Moyroud, and L. Taylor. 2015. How have advances in comparative floral development influenced our understanding of floral evolution? International Journal of Plant Sciences 176: 307-323.

Goodwillie, C., C. Ritland, and K. Ritland. 2006. The genetic basis of floral traits associated with mating system evolution in Leptosiphon (Polemoniaceae): an analysis of quantitative trait loci. Evolution 60: 491-504.

Hansen, T. E. 2013. The evolution of genetic architecture. Annual Review of Ecology, Evolution, and Sytematics 37: 123-157.

Harrell Jr, F. E., with contributions from Charles Dupont, and many others. 2016. Hmisc: Harrell Miscellaneous.

Institute, D. J. G. 2017. Mimulus Genome Project. Institute, DoE Joint Genome. Website http://genome.jgi.doe.gov/mimulus/mimulus.home.html.

Kelly, J. K. 2009. Connecting QTLs to the G-matrix of evolutionary quantitative genetics. Evolution 63: $813-825$.

Kostyun, J. L., M. J. S. S. Gibson, C. M. King, and L. C. Moyle. 2019. A simple genetic architecture and low constraint allows rapid floral evolution in a diverse and recently radiating plant genus. New Phytologist 1: nph.15844.

Krizek, B. A., and J. T. Anderson. 2013. Control of flower size. Journal of Experimental Botany 64: 14271437. 1210-1226. 
713

714

715

Lendvai, G., and D. A. Levin. 2003. Rapid response to artificial selection on flower size in Phlox. Heredity 90: 336-342.

Lin, J., and K. Ritland. 1997. Quantitative trait loci differentiating the outbreeding Mimulus guttatus from the inbreeding M. platycalyx. Genetics 146: 1115-1121.

Nakajima, G. 1963. Karyotype of genus Ipomoea. Cytologia 28: 351-359.

Ornduff, R. 1969. Reproductive biology in relation to systematics. Taxon 18: 121-133.

Peterson, B. K., J. N. Weber, E. H. Kay, H. S. Fisher, and H. E. Hoekstra. 2012. Double digest RADseq: an inexpensive method for de novo SNP discovery and genotyping in model and non-model species. PloS one 7: e37135.

Rastas, P. 2020. Lep-Anchor: automated construction of linkage map anchored haploid genomes. Bioinformatics (Oxford, England) 36: 2359-2364.

Rastas, P., L. Paulin, I. Hanski, R. Lehtonen, P. Auvinen, and M. Brudno. 2013. Lep-MAP: Fast and accurate linkage map construction for large SNP datasets. Bioinformatics 29: 3128-3134.

Rifkin, J. L., A. S. Castillo, I. T. Liao, and M. D. Rausher. 2019. Gene flow, divergent selection and resistance to introgression in two species of morning glories (Ipomoea). Molecular Ecology 28: 1709-1729.

Rifkin, J. L., I. T. Liao, A. S. Castillo, and M. D. Rausher. 2019. Multiple aspects of the selfing syndrome of the morning glory Ipomoea lacunosa evolved in response to selection: A Qst - Fst comparison. Ecology and Evolution: 7712-7725.

Roff, D. A. 1995. The estimation of genetic correlations from phenotypic correlations: A test of Cheverud's conjecture. Heredity 74: 481-490. 
Salih, H., and D. L. Adelson. 2009. QTL global meta-analysis: Are trait determining genes clustered? BMC Genomics 10: 1-8.

Saltz, J. B., F. C. Hessel, and M. W. Kelly. 2017. Trait Correlations in the Genomics Era. Trends in Ecology and Evolution 32: 279-290.

SAS Instititute. 2013. SAS version 9.4.

739

740

Sicard, A., and M. Lenhard. 2011. The selfing syndrome: A model for studying the genetic and evolutionary basis of morphological adaptation in plants. Annals of Botany 107: 1433-43.

Sicard, A., N. Stacey, K. Hermann, J. Dessoly, B. Neuffer, I. Bäurle, and M. Lenhard. 2011. Genetics, evolution, and adaptive significance of the selfing syndrome in the genus Capsella. Plant Cell 23: $3156-3171$.

Slotte, T., K. Hazzouri, and D. Stern. 2012. Genetic architecture and adaptive significance of the selfing syndrome in Capsella. Evolution 66: 1360-1374.

Smith, S. D. 2015. Pleiotropy and the evolution of floral integration. New Phytologist 209: 80-85.

Snell, R., and L. W. Aarssen. 2005. Life history traits in selfing versus outcrossing annuals: exploring the 'time-limitation' hypothesis for the fitness benefit of self-pollination. BMC Ecology 5: 2.

Sowell, D. D. R., and L. L. M. Wolfe. 2010. Pattern and consequences of floral herbivory in four sympatric Ipomoea species. The American Midland Naturalist 163: 173-185.

Stern, D. L. 2013. The genetic causes of convergent evolution. Nature Reviews Genetics 14: 751-64.

Tsuchimatsu, T., H. Kakui, M. Yamazaki, C. Marona, H. Tsutsui, A. Hedhly, D. Meng, et al. 2020. Adaptive reduction of male gamete number in the selfing plant Arabidopsis thaliana. Nature Communications 11: 2885. 
USDA, and NRCS. 2017. The PLANTS Database. National Plant Data Team, Greensboro NC USA.

756

757

758

759

760

761

762

763

Wagner, G. P., and L. Altenberg. 1996. Complex adaptations and the evolution of evolvability. Evolution 50: 967-976.

Waitt, D. E., and D. A. Levin. 1998. Genetic and phenotypic correlations in plants: A botanical test of Cheverud's conjecture. Heredity 80: 310-319.

Wessinger, C. A., and L. C. Hileman. 2016. Accessibility, constraint, and repetition in adaptive floral evolution. Developmental biology: 1-9.

Wickham, H., R. François, L. Henry, and K. Müller. 2020. dplyr: A grammar of data manipulation.

Worley, A. C., and S. C. Barrett. 2000. Evolution of floral display in Eichhornia paniculata

(Pontederiaceae): direct and correlated responses to selection on flower size and number. Evolution 54: 1533-1545.

Woźniak, N. J., C. Kappel, C. Marona, L. Altschmied, B. Neuffer, and A. Sicard. 2020. A similar genetic architecture underlies the convergent evolution of the selfing syndrome in Capsella. The Plant Cell 32: 935-949.

Woźniak, N. J., and A. Sicard. 2018. Evolvability of flower geometry: Convergence in pollinator-driven morphological evolution of flowers. Seminars in Cell \& Developmental Biology 79: 3-15. 


\section{TABLES}

Table 1

Mean trait values from grandparent genotype clones (floral, color, inflorescence, pollen, and nectar traits) or selfed offspring of grandparents (early growth life-history traits) in 2014 growout (2013 values in parentheses). Module is trait group identified by cluster analysis. Asterisks indicate that F2 mean differs significantly from midparent value, or that F1 differed from midparent value in 2013 growout, following a false discovery rate correction.

\begin{tabular}{|c|c|c|c|c|c|c|c|}
\hline Anatomical & $\underline{\text { Cluster }}$ & $\underline{\text { Trait (n F2s }}$ & & I. lacunosa & 1. cordatotriloba & & \\
\hline Module & $\underline{\text { Module }}$ & phenotyped) & Acronym & grandparent & grandparent & $\underline{\text { F1 parent }}$ & $\underline{F 2 \text { mean }}$ \\
\hline Color & -- & Color (356) & COL & 0.00 & 1.00 & 1.00 & $0.79 *$ \\
\hline Floral & & & & 18.78 & 30.74 & 24.55 & \\
\hline morphology & 1 & Corolla Length (356) & $\mathrm{CL}$ & $(16.94)$ & $(28.37)$ & $(22.84)$ & $26.65^{*}$ \\
\hline Floral & & Corolla Shape 1 (CL / & & & & & \\
\hline morphology & 1 & CW) (356) & LW & 1.35 & 1.19 & 1.20 & $1.26^{*}$ \\
\hline Floral & & Corolla Shape 2 (TL/ & & & & & \\
\hline morphology & 1 & CL) (356) & TLL & 1.13 & 1.16 & 1.15 & $1.15^{*}$ \\
\hline
\end{tabular}




\begin{tabular}{|c|c|c|c|c|c|c|c|}
\hline \multicolumn{2}{|l|}{ Floral } & \multicolumn{3}{|l|}{ Corolla Tissue Length } & \multirow[b]{2}{*}{35.53} & \multirow[b]{2}{*}{28.22} & \multirow[b]{2}{*}{$30.73 *$} \\
\hline morphology & 1 & $(356)$ & TL & 21.15 & & & \\
\hline Floral & & & & 13.97 & 26.01 & 20.47 & \\
\hline morphology & 1 & Corolla Width (356) & CW & (13.56) & (24.64) & (19.72) & $21.32 *$ \\
\hline Floral & & & & 11.16 & 17.52 & $15.58 *$ & $15.91^{*}$ \\
\hline morphology & 1 & Style Length (356) & SL & (9.67) & (14.64) & $(13.39)^{*}$ & \\
\hline Inflorescence & 2 & Cyme Length (356) & $\mathrm{CY}$ & 15.88 & 20.92 & 16.05 & $23.02 *$ \\
\hline \multirow[t]{2}{*}{ Inflorescence } & & Flowers and Buds on & & & & & \\
\hline & 2 & Cyme (356) & FC & 1.15 & 1.41 & 1.17 & $1.42^{*}$ \\
\hline \multirow[t]{2}{*}{ Phenology } & & & & 470.61 & 297.28 & & $442.08^{*}$ \\
\hline & 5 & Height (424) & $\mathrm{H}$ & (492.91) & $(334.90)$ & (561.92) & \\
\hline \multirow[t]{2}{*}{ Phenology } & & Length of First & & 15.20 & 6.47 & & \\
\hline & 3 & Internode (424) & INT1 & (13.03) & (6.33) & (10.15) & $11.56^{*}$ \\
\hline \multirow[t]{2}{*}{ Phenology } & & Length of Second & & 17.02 & 7.72 & & \\
\hline & 3 & Internode (424) & INT2 & (22.36) & $(6.86)$ & (17.85) & $16.38 *$ \\
\hline Phenology & & Length of Third & & 67.41 & 22.72 & & \\
\hline & 3 & Internode (424) & INT3 & (79.48) & (26.40) & $(78.31)^{*}$ & $63.27 *$ \\
\hline
\end{tabular}




\begin{tabular}{|c|c|c|c|c|c|c|c|}
\hline \multirow[t]{2}{*}{ Phenology } & \multicolumn{3}{|c|}{ Number of Leaves } & \multirow{2}{*}{$\begin{array}{r}5.74 \\
(7.36)\end{array}$} & \multicolumn{2}{|l|}{6.19} & \\
\hline & 5 & $(424)$ & NL & & (8.59) & $(9.92)$ & 5.96 \\
\hline Phenology & 2 & Flowering Date (356) & FD & N/A & N/A & N/A & 158.62 \\
\hline \multirow[t]{2}{*}{ Phenology } & & \multicolumn{2}{|l|}{ Number of Flowers } & & & & \\
\hline & & Measured (419) & NF & N/A & N/A & N/A & 3.14 \\
\hline \multirow[t]{2}{*}{ Phenology } & & \multicolumn{2}{|l|}{ Number of Flowers } & & & & \\
\hline & $4^{1}$ & Open (356) & FPD & N/A & N/A & $\mathrm{N} / \mathrm{A}$ & 1.29 \\
\hline Phenology & & Ever Flowered (419) & EF & N/A & N/A & N/A & 0.834 \\
\hline \multirow[t]{2}{*}{ Phenology } & & First Leaf Opening & & 11.53 & 11.22 & & \\
\hline & 5 & (419) & L1 & (13.54) & $(12.86)$ & $(12.00)^{*}$ & 11.62 \\
\hline \multirow[t]{2}{*}{ Phenology } & 5 & Second Leaf Opening & L2 & 13.78 & 13.07 & & 13.60 \\
\hline & & $(416)$ & & (15.95) & (15.09) & (14.31) & \\
\hline \multirow[t]{2}{*}{ Phenology } & & Third Leaf Opening & & 16.04 & 15.50 & & 15.88 \\
\hline & 5 & (401) & L3 & (18.64) & (18.10) & $(17.00)$ & \\
\hline Nectar & $1(2)^{1}$ & Nectar Volume (356) & NVL & 0.00 & 1.31 & 0.40 & $0.21 *$ \\
\hline Pollen & 4 & Pollen Count 1, (69) & P1 & 140.00 & 706.00 & 323.50 & $204.48 *$ \\
\hline
\end{tabular}




\begin{tabular}{|c|c|c|c|c|c|c|c|}
\hline Pollen & 4 & Pollen Count 2, (110) & P2 & 450.00 & 946.25 & 251.25 & $350.03 *$ \\
\hline Pollen & 4 & Pollen Size, (69) & PS & 69.54 & 81.29 & 71.85 & $69.32 *$ \\
\hline & $4^{1}$ & Herkogamy² (356) & HK & -0.08 & -0.03 & 0.00 & $0.01 *$ \\
\hline
\end{tabular}

${ }^{1}$ Placed in different modules by different cluster analyses. Module not in parentheses is the module the trait clustered with in the majority of clustering analyses.

${ }^{2}$ Removed from downstream analyses because of lack of segregating variation in F2s 


\section{Table 2}

Average pairwise trait correlations (and standard error) within (main diagonal) and between (offdiagonal) modules. Within module averages calculated as the average of correlations for all possible trait pairs within the module. Between module averages calculated as average of correlations between a trait in one module and a trait in the second module. Mean within-module correlation $=0.509$. Mean between-module correlation $=0.105$. Difference significant by permutation test $(P<0.001)$.

\begin{tabular}{|l|l|l|l|l|l|}
\hline & Module 1 & Module 2 & Module 3 & Module 4 & Module 5 \\
\hline Module 1 & 0.404 (0.057)* & $0.155(0.027)$ & $0.039(0.006)$ & $0.069(0.009)$ & $0.055(0.005)$ \\
\hline Module 2 & & $0.366(0.096)$ & $0.050(0.019)$ & $0.108(0.026)$ & $0.090(0.028)$ \\
\hline Module 3 & & & $0.607(0.10)$ & $0.126(0.028)$ & $0.175(0.041)$ \\
\hline Module 4 & & & & $0.342(0.082)$ & $0.230(0.030)$ \\
\hline Module 5 & & & & & $0.844(0.026)$ \\
\hline
\end{tabular}




\section{Table 3}

Average QTL overlap (and standard error) within and between anatomical and cluster-based modules.

A. Only QTLs exhibiting genome-wide significance. Average overlap (and standard error) within modules $=0.320$ (0.067). Average overlap between modules $=0.0368(0.014)$. Difference significant at $\mathrm{P}<0.001$ (permutation test). B. All QTLs. Average overlap (and standard error) within modules $=0.320(0.036)$. Average overlap between modules $=0.056(0.008)$. Difference significant at $P<0.001$ (permutation test).

\section{A. GWS QTLS}

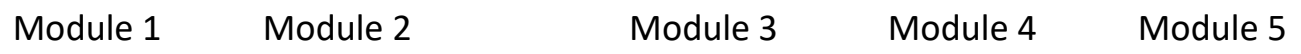

\begin{tabular}{|l|l|l|l|l|l|}
\hline Module 1 & $0.201(0.064)$ & $0.024(0.024)$ & $0.000(0.000)$ & $0.000(0.000)$ & $0.000(0.000)$ \\
\hline Module 2 & & $0.000(0.000)$ & $0.000(0.000)$ & $0.000(\mathrm{NA})$ & $0.000(0.000)$ \\
\hline Module 3 & & & $1.000(1.000)$ & $0.000(0.000)$ & $0.333(0.077)$ \\
\hline Module 4 & & & & $0.000(0.000)$ & $0.000(0.000)$ \\
\hline Module 5 & & & & & $0.625(0.100)$ \\
\hline
\end{tabular}

\section{B. All QTLS}

$\begin{array}{lllll}\text { Module } 1 & \text { Module } 2 & \text { Module } 3 & \text { Module } 4 & \text { Module } 5\end{array}$

\begin{tabular}{|l|l|l|l|l|l|}
\hline Module 1 & $0.299(0.053)$ & $0.112(0.026)$ & $0.044(0.015)$ & $0.064(0.017)$ & $0.025(0.008)$ \\
\hline Module 2 & & $0.178(0.097)$ & $0.019(0.019)$ & $0.021(0.021)$ & $0.011(0.011)$ \\
\hline Module 3 & & & $0.367(0.117)$ & $0.033(0.022)$ & $0.225(0.060)$ \\
\hline Module 4 & & & & $0.222(0.102)$ & $0.010(0.010)$ \\
\hline
\end{tabular}


bioRxiv preprint doi: https://doi.org/10.1101/2021.01.14.426677; this version posted January 14, 2021. The copyright holder for this preprint (which was not certified by peer review) is the author/funder. All rights reserved. No reuse allowed without permission.

\begin{tabular}{|l|l|l|l|l|l|}
\hline Module 5 & & & & & $0.452(0.065)$ \\
\hline
\end{tabular}




\section{Table 4}

Studies included in our quantitative review of QTL overlap, using anatomical modules. Modules abbreviations are F (floral morphology), C (color traits), I (inflorescence traits), Ph (phenology traits including growth rate and flowering time), $\mathrm{N}$ (nectar), Po (pollen), $\mathrm{R}$ (reproductive traits such as compatibility), and $\mathrm{V}$ (vegetative traits distinct from timing, such as leaf size).

\begin{tabular}{|c|c|c|c|c|c|c|}
\hline $\begin{array}{l}\text { Species } \\
\text { (Family) }\end{array}$ & Included traits & $\begin{array}{l}\text { Included } \\
\text { modules }\end{array}$ & $\begin{array}{l}\text { Within- } \\
\text { module } \\
\text { overlap }\end{array}$ & $\begin{array}{l}\text { Between- } \\
\text { module } \\
\text { overlap }\end{array}$ & $\begin{array}{l}\text { Overall } \\
\text { overlap }\end{array}$ & Citation \\
\hline $\begin{array}{l}\text { Mimulus } \\
\text { guttatus and } M . \\
\text { platycalyx } \\
\text { (Phrymaceae) }\end{array}$ & $\begin{array}{l}\text { Flower width } \\
\text { (F), flower } \\
\text { length (F), } \\
\text { pistil length } \\
\text { (F), long } \\
\text { stamen length } \\
\text { (F), short } \\
\text { stamen length } \\
\text { (F), } \\
\text { herkogamy (R) }\end{array}$ & $\begin{array}{l}\text { Floral } \\
\text { morphology }\end{array}$ & 0.144 & 0 & 0.087 & $\begin{array}{l}\text { Lin and } \\
\text { Ritland, } \\
1997\end{array}$ \\
\hline $\begin{array}{l}\text { Solanum } \\
\text { habrochaites } \\
\text { and S. } \\
\text { esculentum } \\
\text { (Solanaceae) }\end{array}$ & $\begin{array}{l}\text { Stigma } \\
\text { exsertion (F), } \\
\text { bud type (F), } \\
\text { corolla } \\
\text { indentation }\end{array}$ & $\begin{array}{l}\text { Floral } \\
\text { morphology, } \\
\text { inflorescence, } \\
\text { phenology, }\end{array}$ & 0.143 & 0.229 & 0.227 & $\begin{array}{l}\text { Bernacchi } \\
\text { and } \\
\text { Tanksley, } \\
1999\end{array}$ \\
\hline
\end{tabular}




\begin{tabular}{|c|c|c|c|c|c|c|}
\hline & $\begin{array}{l}\text { (F), flower size } \\
(\mathrm{F}) \text {, rachis } \\
\text { length (I), } \\
\text { inflorescence } \\
\text { vegetative } \\
\text { meristem } \\
\text { presence (I), } \\
\text { number of } \\
\text { flowers per } \\
\text { plant (Ph), } \\
\text { self- } \\
\text { incompatibility } \\
\text { (R), unilateral } \\
\text { incongruity (R) }\end{array}$ & $\begin{array}{l}\text { reproductive } \\
\text { traits }\end{array}$ & & & & \\
\hline $\begin{array}{l}\text { Mimulus } \\
\text { guttatus and } M \text {. } \\
\text { nasutus } \\
\text { (Phrymaceae) }\end{array}$ & $\begin{array}{l}\text { Throat width } \\
\text { (F), corolla } \\
\text { width (F), tube } \\
\text { length, (F), } \\
\text { corolla length } \\
\text { (F), style } \\
\text { length (F), } \\
\text { stamen length } \\
\text { (F), } \\
\text { herkogamy }\end{array}$ & $\begin{array}{l}\text { Floral } \\
\text { morphology }\end{array}$ & 0.343 & N/A & 0.343 & $\begin{array}{l}\text { Fishman } \\
\text { and Willis, } \\
2002\end{array}$ \\
\hline
\end{tabular}




\begin{tabular}{|c|c|c|c|c|c|c|}
\hline $\begin{array}{l}\text { Solanum } \\
\text { pimpinellifolium } \\
\text { (Solanaceae) }\end{array}$ & $\begin{array}{l}\text { Anther total } \\
\text { length (F), } \\
\text { anther sterile } \\
\text { length (F), } \\
\text { style length } \\
\text { (F), flowers } \\
\text { per } \\
\text { inflorescence } \\
\text { (I). }\end{array}$ & $\begin{array}{l}\text { Floral } \\
\text { morphology, } \\
\text { inflorescence }\end{array}$ & 0.167 & 0.5 & 0.333 & $\begin{array}{l}\text { Georgiady } \\
\text { et al., } 2002\end{array}$ \\
\hline $\begin{array}{l}\text { Leptosiphon } \\
\text { bicolor and L. } \\
\text { jepsonii }\end{array}$ & $\begin{array}{l}\text { Corolla tube } \\
\text { length (F), } \\
\text { corolla lobe } \\
\text { length (F), } \\
\text { corolla lobe } \\
\text { width (F), } \\
\text { anther length } \\
\text { (F), stigma } \\
\text { length (F) }\end{array}$ & $\begin{array}{l}\text { Floral } \\
\text { morphology }\end{array}$ & 0.301 & N/A & 0.301 & $\begin{array}{l}\text { Goodwillie } \\
\text { et al. } 2006\end{array}$ \\
\hline $\begin{array}{l}\text { Capsella rubella } \\
\text { and C. } \\
\text { grandiflora } \\
\text { (Brassicaceae) }\end{array}$ & $\begin{array}{l}\text { Petal area (F), } \\
\text { petal length } \\
(F) \text {, petal } \\
\text { width (F), } \\
\text { petal opening } \\
\text { angle (F), }\end{array}$ & $\begin{array}{l}\text { Floral } \\
\text { morphology, } \\
\text { reproductive } \\
\text { traits, } \\
\text { vegetative } \\
\text { traits }\end{array}$ & 0.643 & 0.256 & 0.326 & $\begin{array}{l}\text { Sicard et } \\
\text { al. } 2011\end{array}$ \\
\hline
\end{tabular}




\begin{tabular}{|c|c|c|c|c|c|c|}
\hline & $\begin{array}{l}\text { herkogamy } \\
\text { (R), leaf area } \\
\text { (V), leaf width } \\
\text { (V), leaf length } \\
\text { (V) }\end{array}$ & & & & & \\
\hline $\begin{array}{l}\text { Capsella rubella } \\
\text { and C. } \\
\text { grandiflora } \\
\text { (Brassicaceae) }\end{array}$ & $\begin{array}{l}\text { Lateral stamen } \\
\text { length (F), } \\
\text { median } \\
\text { stamen length } \\
\text { (F), petal } \\
\text { length (F), } \\
\text { petal width } \\
\text { (F), style and } \\
\text { gynoecium } \\
\text { length (F), } \\
\text { days to } \\
\text { flowering (Ph), } \\
\text { leaf number at } \\
\text { length (F), } \\
\text { flowering (Ph), } \\
\text { lateral sepal } \\
\text { self- }\end{array}$ & $\begin{array}{l}\text { Floral } \\
\text { morphology, } \\
\text { inflorescence, } \\
\text { phenology, } \\
\text { reproductive } \\
\text { traits, pollen }\end{array}$ & 0.284 & 0.137 & 0.202 & $\begin{array}{l}\text { Slotte et } \\
\text { al. } 2012\end{array}$ \\
\hline
\end{tabular}




\begin{tabular}{|c|c|c|c|c|c|c|}
\hline & $\begin{array}{l}\text { compatibility } \\
\text { (R), homeotic } \\
\text { floral } \\
\text { aberrations } \\
\text { (R), ovule } \\
\text { number (R), } \\
\text { pollen number } \\
\text { (P) }\end{array}$ & & & & & \\
\hline $\begin{array}{l}\text { Mimulus lewisii } \\
\text { and M. parishii } \\
\text { (Phrymaceae) }\end{array}$ & $\begin{array}{l}\text { Corolla width } \\
\text { (F), corolla } \\
\text { length (F), } \\
\text { long stamen } \\
\text { (F), pistil } \\
\text { length (F), } \\
\text { stigma-anther } \\
\text { separation (R), } \\
\text { throat width } \\
\text { (F), corolla } \\
\text { tube length } \\
\text { (F), calyx } \\
\text { length (I), time } \\
\text { to flowering } \\
\text { (Ph), anther } \\
\text { sterility (R) }\end{array}$ & $\begin{array}{l}\text { Floral } \\
\text { morphology, } \\
\text { inflorescence, } \\
\text { phenology, } \\
\text { reproductive } \\
\text { traits }\end{array}$ & 0.483 & 0.162 & 0.260 & $\begin{array}{l}\text { Fishman et } \\
\text { al. } 2014\end{array}$ \\
\hline
\end{tabular}




\begin{tabular}{|c|c|c|c|c|c|c|}
\hline $\begin{array}{l}\text { Capsella } \\
\text { orientalis, C. } \\
\text { rubella, and C. } \\
\text { grandiflora }\end{array}$ & $\begin{array}{l}\text { Petal area (F), } \\
\text { petal length } \\
\text { (F), petal } \\
\text { width (F), } \\
\text { ovule number } \\
\text { (R), self- } \\
\text { incompatibility } \\
\text { (R), leaf area } \\
\text { (V) } \\
\text { C. orientalis - } \\
\text { C. grandiflora } \\
\text { /C. orientalis } \\
\text { - C. rubella }\end{array}$ & $\begin{array}{l}\text { Floral } \\
\text { morphology, } \\
\text { reproductive } \\
\text { traits, } \\
\text { vegetative } \\
\text { traits }\end{array}$ & $\begin{array}{l}0.285 / \\
0.222\end{array}$ & $\begin{array}{l}0.108 / \\
0.194\end{array}$ & $\begin{array}{l}0.159 / \\
0.208\end{array}$ & $\begin{array}{l}\text { Wózniak et } \\
\text { al. } 2020\end{array}$ \\
\hline $\begin{array}{l}\text { Ipomoea } \\
\text { lacunosa and I. } \\
\text { cordatotriloba }\end{array}$ & $\begin{array}{l}\text { (see Table 1) } \\
\text { CWS / GWS }\end{array}$ & $\begin{array}{l}\text { Floral } \\
\text { morphology, } \\
\text { inflorescence, } \\
\text { nectar, } \\
\text { pollen, live } \\
\text { history }\end{array}$ & $\begin{array}{l}0.406 / \\
0.235\end{array}$ & $\begin{array}{l}0.104 / \\
0.025\end{array}$ & $\begin{array}{l}0.166 / \\
0.114\end{array}$ & This study \\
\hline
\end{tabular}




\section{FIGURE CAPTIONS}

Figure 1: Locations of QTLs in the genome. A: All QTLs. B: GWS QTLs.

Figure 2: Relationship between QTL overlap and phenotypic correlations. A and B: All pairwise trait values of QTL overlap and phenotypic correlation. A. All QTLs. Correlation significant by permutation test $(P<0.001)$. B. Only GWS QTLs. Correlation not significant by permutation test $(P=0.233)$. C and $D$ : Average within- and between-module values. C. All QTLs. Correlation significant by permutation test $(P=$ 0.005). D. Only GWS QTLs. Correlation not significant by permutation test $(P=0.113)$.

Figure 3: Correlation between phenotypic and predicted genetic correlations. A. - D. Pairwise trait correlations. A and B: all QTLS . C and D: GWS QTLs. A and C: for all trait pairs. B and D: only trait pairs with predicted non-zero genetic correlations. Permutation tests for significance of correlation: A - D. P <

0.001. E. - F. Module average pairwise correlations. E. All QTLs. $P=0.011$. F. GWS QTLs. $P=0.066$. 
Figure 1: Locations of QTLs in the genome. A: All QTLs. B: GWS QTLs.

A

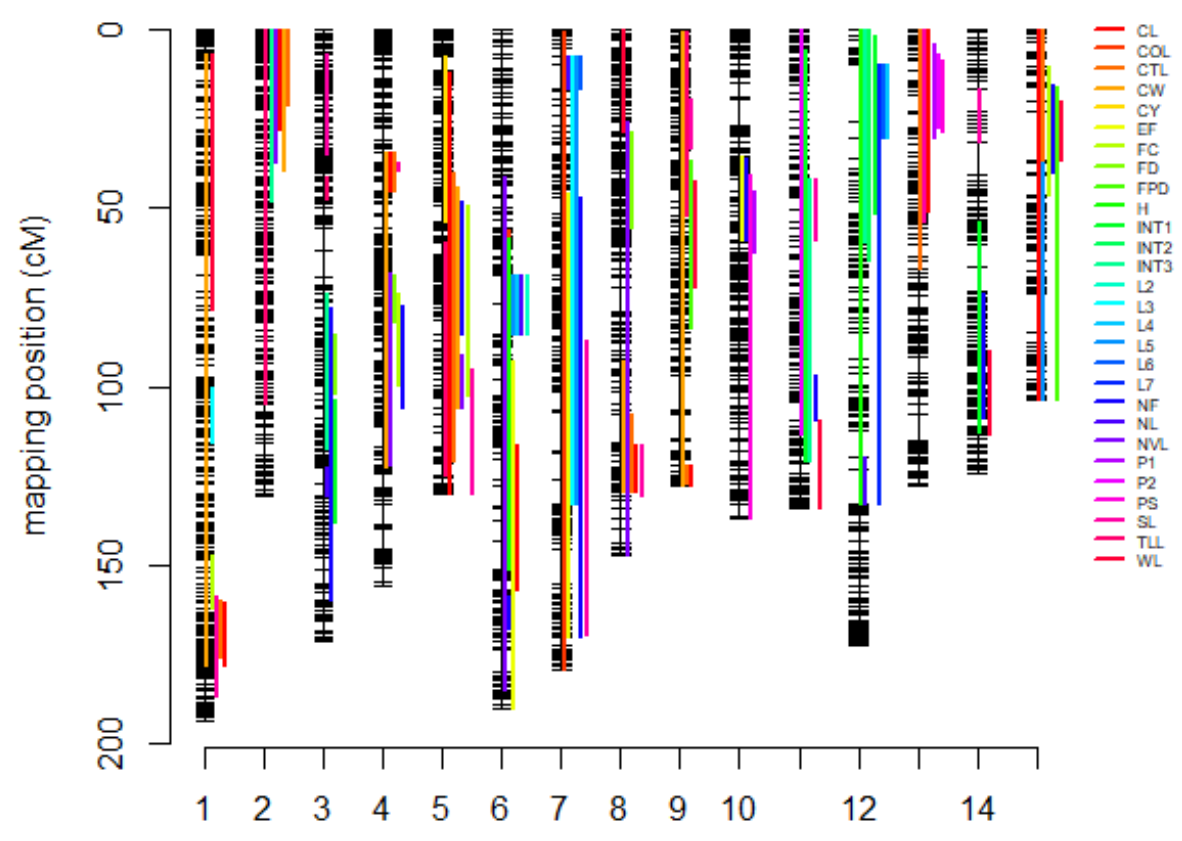

B

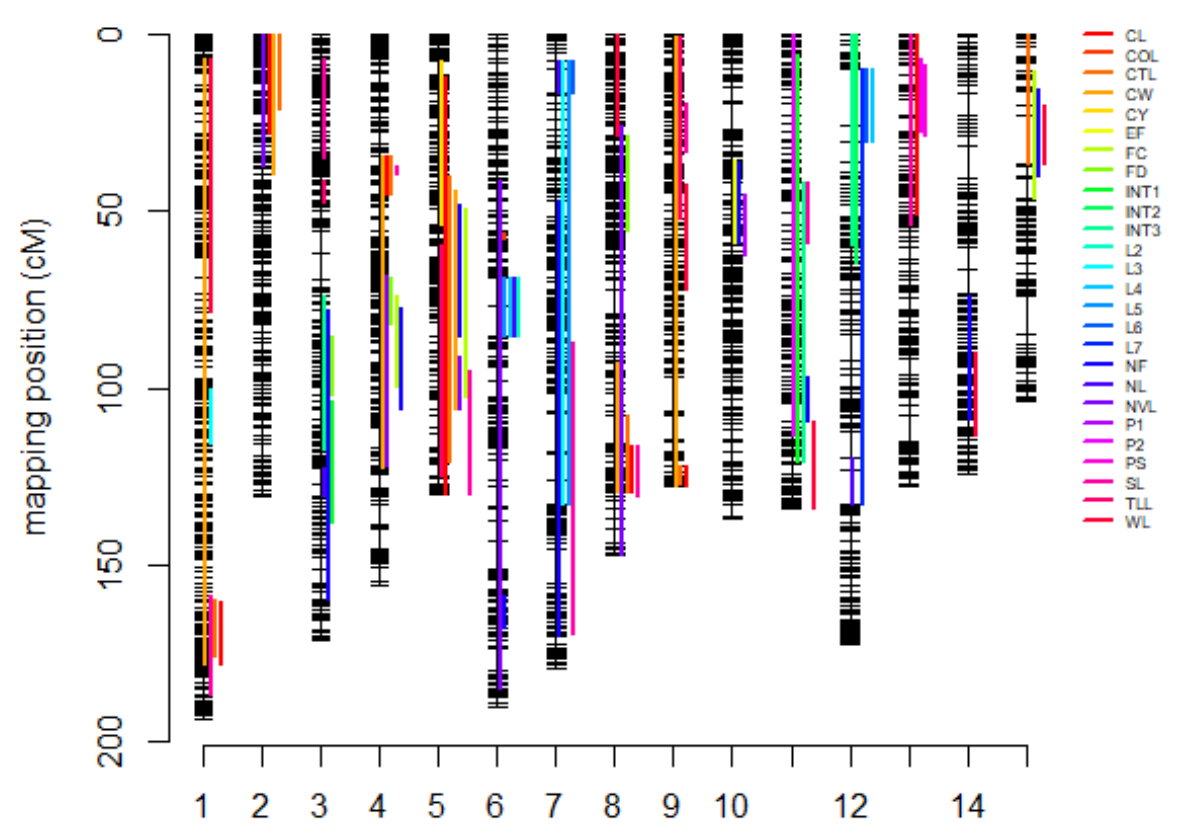


Figure 2: Relationship between QTL overlap and phenotypic correlations. A and B: All pairwise trait values of QTL overlap and phenotypic correlation. A. All QTLs. Correlation significant by permutation test $(P<0.001)$. B. Only GWS QTLs. Correlation not significant by permutation test $(P=0.233)$. C and $D$ :

Average within- and between-module values. C. All QTLs. Correlation significant by permutation test $(P=$ 0.005). D. Only GWS QTLs. Correlation not significant by permutation test ( $P=0.113)$.

A

B
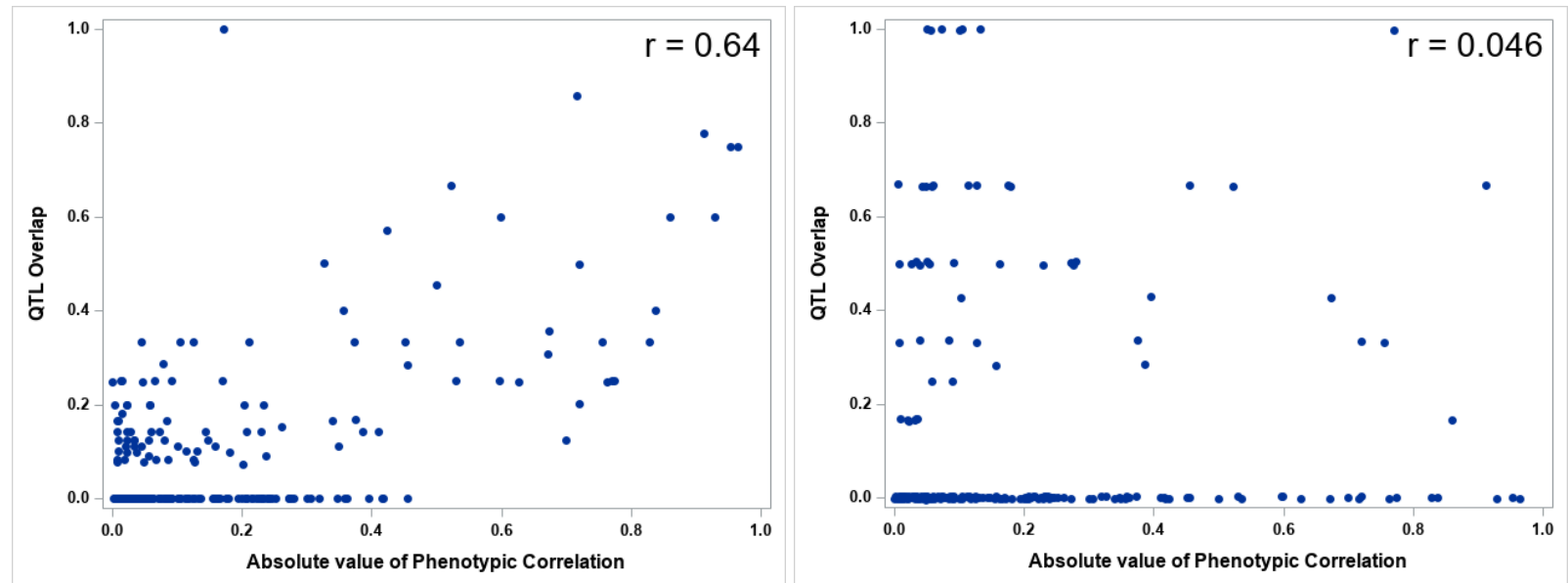

C

D
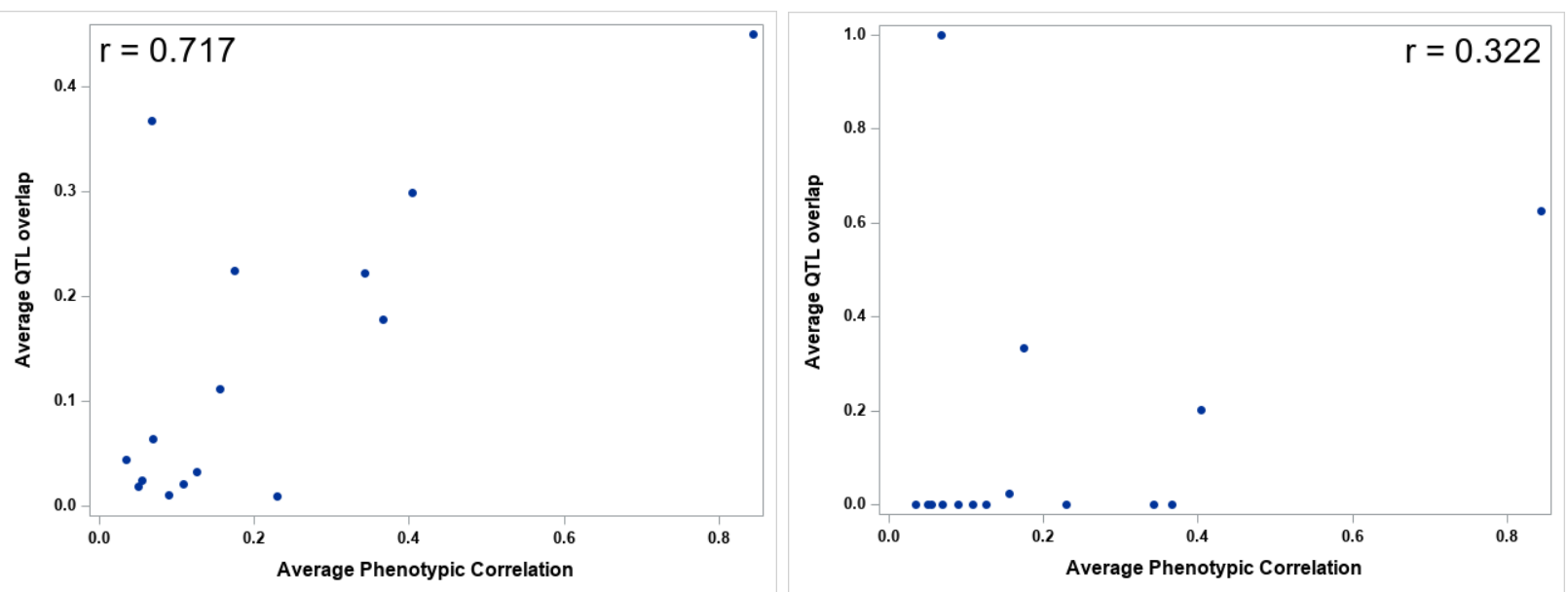
Figure 3: Correlation between predicted genetic and phenotypic correlations. A. - D. Pairwise trait correlations. A and B: all QTLS . C and D: GWS QTLs. A and C: for all trait pairs. B and D: only trait pairs with predicted non-zero genetic correlations. Permutation tests for significance of correlation: $A-D$. $P<$ 0.001. E. - F. Module average pairwise correlations. E. All QTLS. $P=0.011$. F. GWS QTLS. $P=0.066$.

A

B
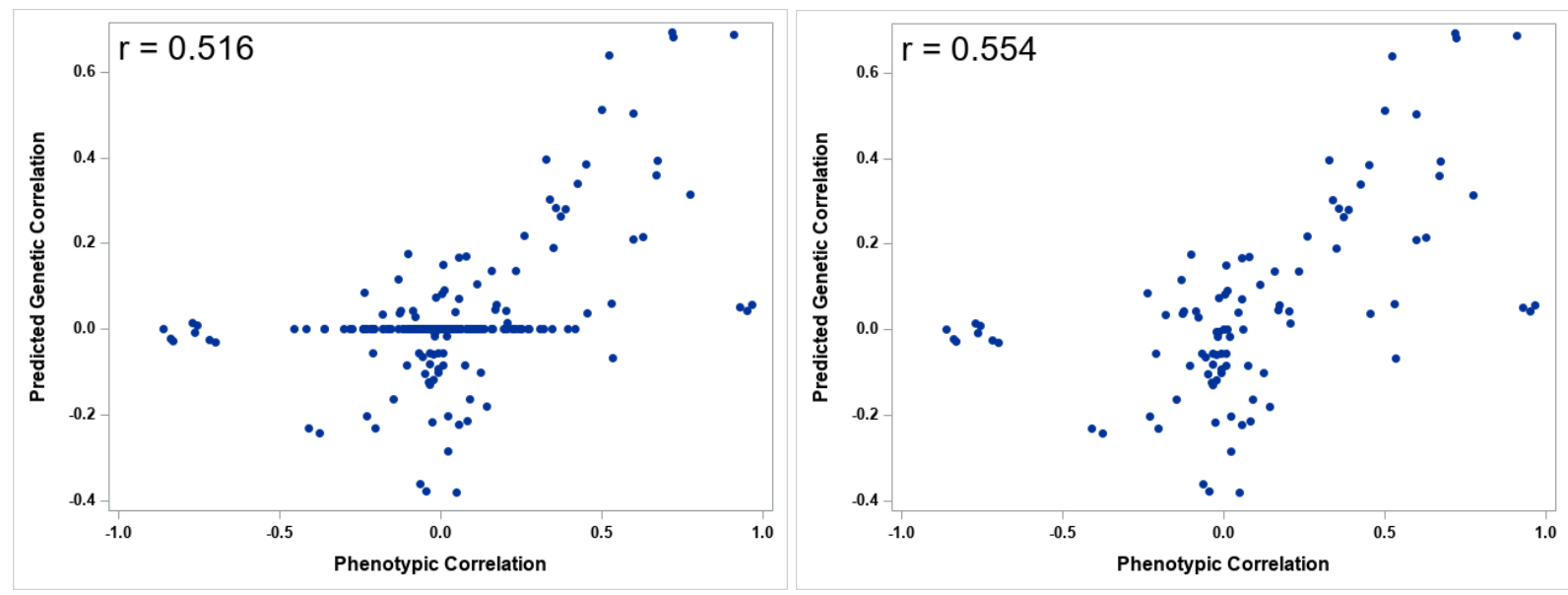

C

D
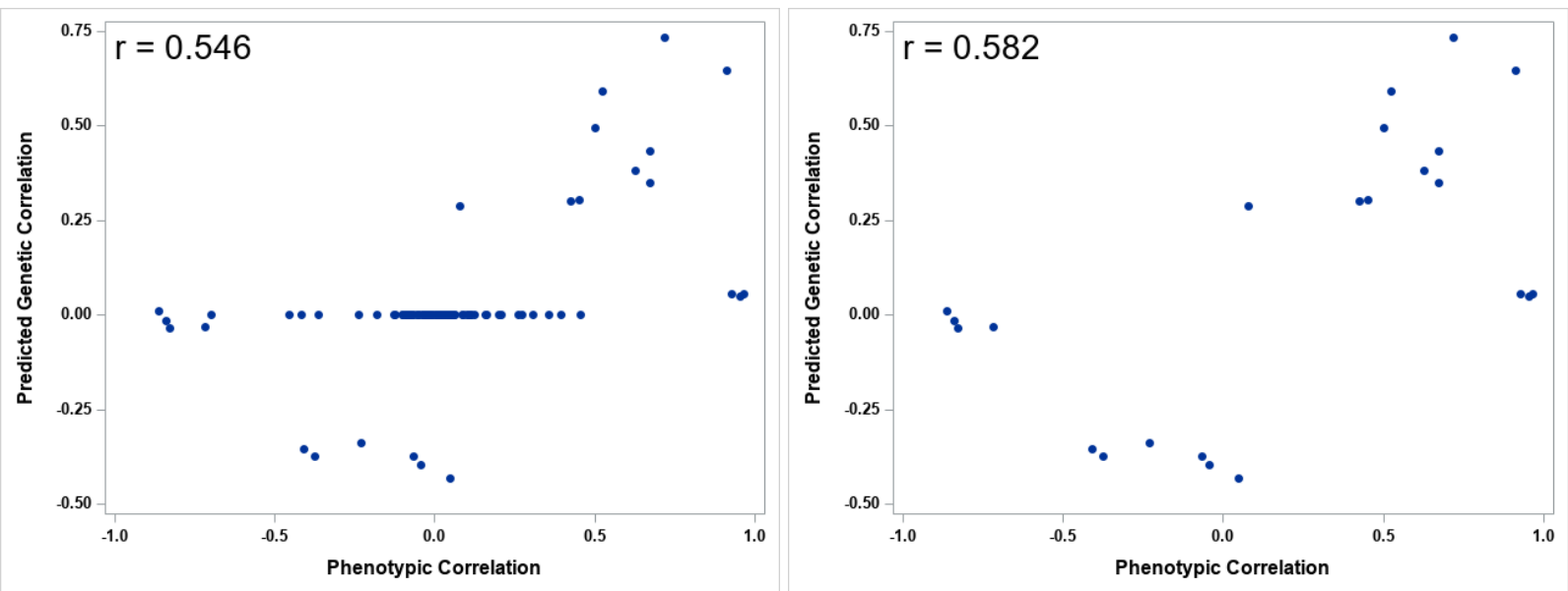
bioRxiv preprint doi: https://doi.org/10.1101/2021.01.14.426677; this version posted January 14, 2021. The copyright holder for this preprint (which was not certified by peer review) is the author/funder. All rights reserved. No reuse allowed without permission.
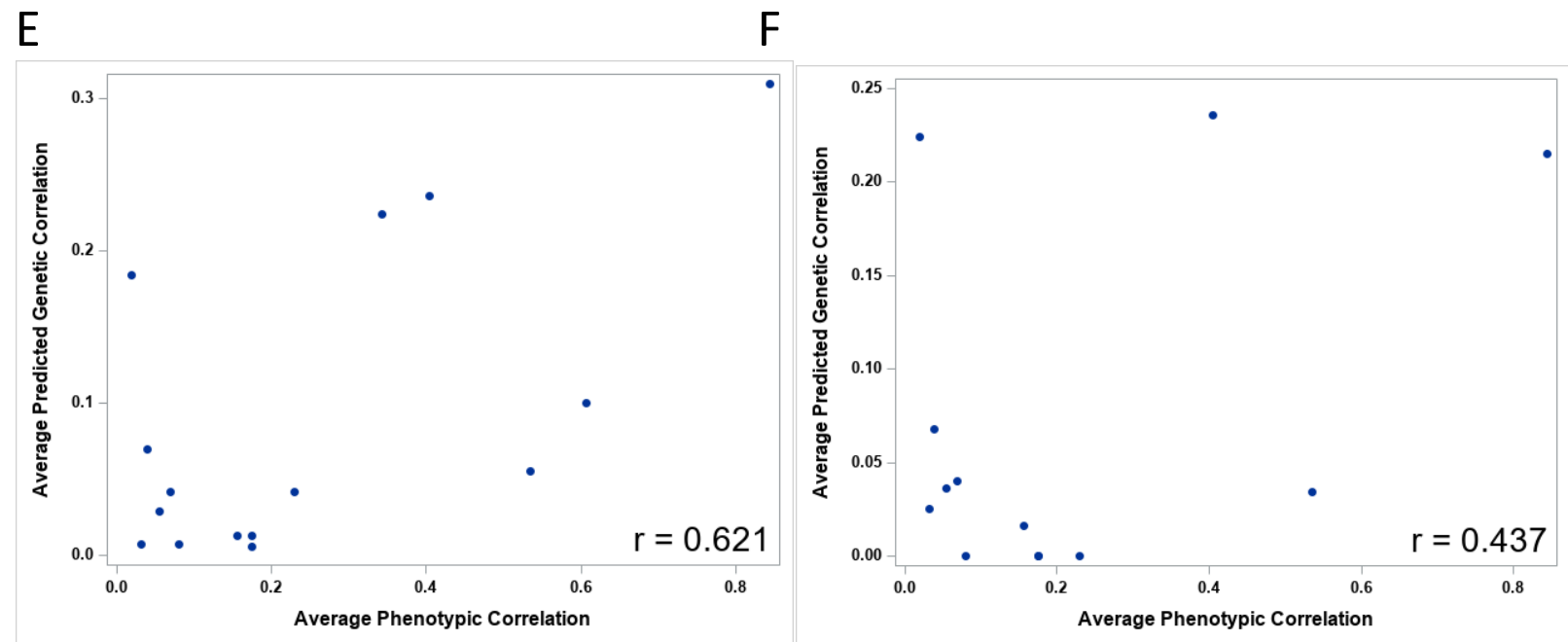